\title{
Roles of Exosomes in Ocular Diseases
}

This article was published in the following Dove Press journal:

International Journal of Nanomedicine

Jia Liu'
Feng Jiang
Yu Jiang'
Yicheng Wang'
Zelin Li'
Xuefeng Shi ${ }^{3-6}$
Yanping Zhu'
Hongbo Wang'
Zhuhong Zhang'

'School of Pharmacy, Key Laboratory of Molecular Pharmacology and Drug Evaluation (Yantai University), Ministry of Education, Collaborative Innovation Center of Advanced Drug Delivery System and Biotech Drugs in Universities of Shandong, Yantai University, Yantai 264005, People's Republic of China; ${ }^{2}$ Department of Ophthalmology, Tianjin Medical University General Hospital, Tianjin 300052, People's Republic of China; ${ }^{3}$ Department of Pediatric Ophthalmology and Strabismus, Tianjin Eye Hospital, Tianjin, 300020, People's Republic of China; ${ }^{4}$ School of Medicine, Nankai University, Tianjin, 30007I, People's Republic of China; ${ }^{5}$ Clinical College of Ophthalmology, Tianjin Medical University, Tianjin 300020, People's Republic of China; ${ }^{6}$ Tianjin Key Laboratory of Ophthalmology and Visual Science, Tianjin Eye Institute, Tianjin 300020, People's Republic of China

Correspondence: Zhuhong Zhang Email zhzhang0608@ytu.edu.cn

\begin{abstract}
Exosomes, nanoscale vesicles with a diameter of 30 to $150 \mathrm{~nm}$, are composed of a lipid bilayer, protein, and genetic material. Exosomes are secreted by virtually all types of cells in the human body. They have key functions in cell-to-cell communication, immune regulation, inflammatory response, and neovascularization. Mounting evidence indicates that exosomes play an important role in various diseases, such as cancer, cardiovascular diseases, and brain diseases; however, the role that exosomes play in eye diseases has not yet been rigorously studied. This review covers current exosome research as it relates to ocular diseases including diabetic retinopathy, age-related macular degeneration, autoimmune uveitis, glaucoma, traumatic optic neuropathies, corneal diseases, retinopathy of prematurity, and uveal melanoma. In addition, we discuss recent advances in the biological functions of exosomes, focusing on the toxicity of exosomes and the use of exosomes as biomarkers and drug delivery vesicles. Finally, we summarize the primary considerations and challenges to be taken into account for the effective applications of exosomes.
\end{abstract}

Keywords: extracellular vesicles, exosomes, retina, ocular diseases, drug delivery

\section{Introduction}

Extracellular vesicles (EVs) are an umbrella term for all lipid bilayer-encased extracellular structures, which are typically divided into three subtypes: exosomes ( $\sim 30-150 \mathrm{~nm}$ in diameter), microvesicles $(\sim 100-1000 \mathrm{~nm}$ in diameter), and apoptotic bodies $(\sim 100-5000 \mathrm{~nm}$ in diameter), based on their formation mode, particle size, and functional properties. ${ }^{1,2}$ Exosomes are the smallest subtype of EVs. ${ }^{2}$ The term "exosome" was first used in the early 1980s to describe small vesicles ( 50 $\mathrm{nm}$ ) of endosomal origin released during the maturation of sheep. ${ }^{3-5}$ Subsequently, it was shown that these nanovesicles could be secreted by numerous cells such as B cells, T cells, cancer cells, endothelial cells, and mesenchymal stem cells. ${ }^{6}$ Exosomes, which are nanosized membrane-enclosed vesicles of 30 to $150 \mathrm{~nm}$ that are shed by various cell types, exist extensively in a variety of bodily fluids including tears, aqueous humor, vitreous humor, blood, urine, semen, vaginal fluid, breast milk, cerebrospinal fluid, ascites, lymph, bile, amniotic fluid, and saliva. ${ }^{7-10}$ They are formed as intraluminal vesicles (ILVs) after fusion of a multivesicular body (MVB) with the plasma membrane. ${ }^{11,12}$ A MVB is an intermediate endosomal compartment that is filled with ILVs. ${ }^{13}$ Diverse bioactive molecules including lipids, proteins, and nucleic acids are the main functional components of exosomes, which are encapsulated in a lipid bilayer membrane. ${ }^{14,15}$ Exosomes are a promising field of cytological and biomedical research, attracting intense interest because of the biological functions and broad contribution of exosomes to a range of diseases. First, exosomes that carry surface molecules partake in intercellular communication 
by activating cellular signaling through receptor-ligand interactions with target cells. ${ }_{-}^{16}$ Second, it has been suggested that exosomes are involved in the progression of multiple diseases through a mechanism by which they change the physiological state of target cells via fusing with the target cell's membrane and transferring their cargo (protein, lipids, mRNA, microRNA, and DNA) to that cell. ${ }^{16-19}$ Third, exosomes have great potential as biomarkers for diagnosing diseases. ${ }^{20-22}$ Finally, exosomes, in the form of drug delivery vehicles, have been explored as potential therapeutic tools for a variety of currently incurable diseases. ${ }^{9,23-26}$

Vision impairment, including blindness, is an important public health concern. ${ }^{27,28}$ The number of people affected by vision impairment or blindness is estimated to be 2.2 billion worldwide with middle-aged and elderly individuals being particularly affected. ${ }^{28-30}$ In 2019, the World Health Organization reported that the leading causes of moderate or severe vision impairment are uncorrected refractive error, cataract, diabetic retinopathy (DR), age-related macular degeneration (AMD), glaucoma, corneal opacity, and trachoma. ${ }^{29}$ The cornea is the transparent front surface of the eye. Characterized by its powerful refractive ability, the cornea is a key component of the optical system. ${ }^{31,32}$ Thus, other diseases of the cornea are contributing factors to vision impairment. In addition to these eye diseases, uveitis, which is uncommon but affects all age, is another cause of vision impairment. ${ }^{33}$ There are many drawbacks and limitations to current therapies such as surgery, intraocular injections, and eye drops that primarily rely on impeding the development of these diseases. Research into more effective alternative treatments is needed, including research into regenerative cell-based therapies. $^{34,35}$

Exosomes are known to play an important role in many diseases, such as cancer, cardiovascular disease, and nervous system diseases. In recent years, the role of various cell-derived exosomes in diverse ophthalmic diseases has been increasingly studied. However, knowledge regarding the function of exosomes in ocular diseases remains limited. Recently, some reviews of the role of exosomes in ocular diseases have emerged. Klingeborn et $\mathrm{al}^{10}$ summarized various studies on the functions of exosomes in the normal and diseased eye, including AMD, diabetic retinopathy, and uveal melanoma. In addition, how exosomes are acquired and their potential as therapeutic carriers and for disease diagnosis are discussed in their review. Mead et $\mathrm{al}^{36}$ reviewed the therapeutic potential of EVs in retinal diseases, including optic nerve crush, glaucoma, retinal ischemia, retinal laser injury, autoimmune uveitis, and diabetic retinopathy. Moreover, they discussed several future research directions. More recently, one review discussed the involvement of exosomes in various pathological processes and their role in several major eye diseases, including autoimmune diseases of the eye, large area corneal damage, retinopathy of prematurity, age-related macular degeneration, diabetic retinopathy, and glaucoma. ${ }^{37}$ Compared with the above reviews, we report here the latest progress on more eye diseases that involve the exosomes. We discuss the role of exosomes in diabetic retinopathy, AMD, autoimmune uveitis, glaucoma, traumatic optic neuropathies, corneal diseases, retinopathy of prematurity and uveal melanoma, and we separately discuss the relationship between exosomes and oxidative stress-induced eye diseases. In addition, we discuss the biogenesis and characteristics of exosomes in detail, as well as extraction methods for studying exosomes, and summarize this in the form of a schematic for clear understanding. Furthermore, we also review the latest research on advancements elucidating the potential applications of exosomes as biomarkers, drug delivery systems, targeting modalities, and as toxic agents.

\section{Characteristics and Biogenesis of Exosomes}

EVs are continually released by most cells into the extracellular space as vehicles to participate in diverse biological processes. EVs have two different pathways of biogenesis: 1) They are produced directly through budding from the plasma membrane; 2) The fusion between a MVB and the plasma membrane forms EVs. The latter is the production pathway of exosomes. ${ }^{38,39}$ As shown in Figure 1, the biosynthesis of exosomes is an endosomal-dependent, progressive cytological process. ILVs accumulate in the lumen when the early endosomes formed by invagination of cell membrane mature into late endosomes. Specific-sorted ILVs, loaded with lipids, proteins, and cytosol, are obtained from inward budding of the early endosomal membrane. Late endosomes filled with ILVs are commonly known as MVBs or multivesicular endosomes (MVEs). ${ }^{8,40}$ There are two fates for the MVB in cells. These are the fusion of an MVB with lysosomes that degrade their cargo, and the fusion between a MVB and the plasma membrane that releases ILVs into extracellular environment as exosomes. ${ }^{41}$ During the formation of exosomes, several 


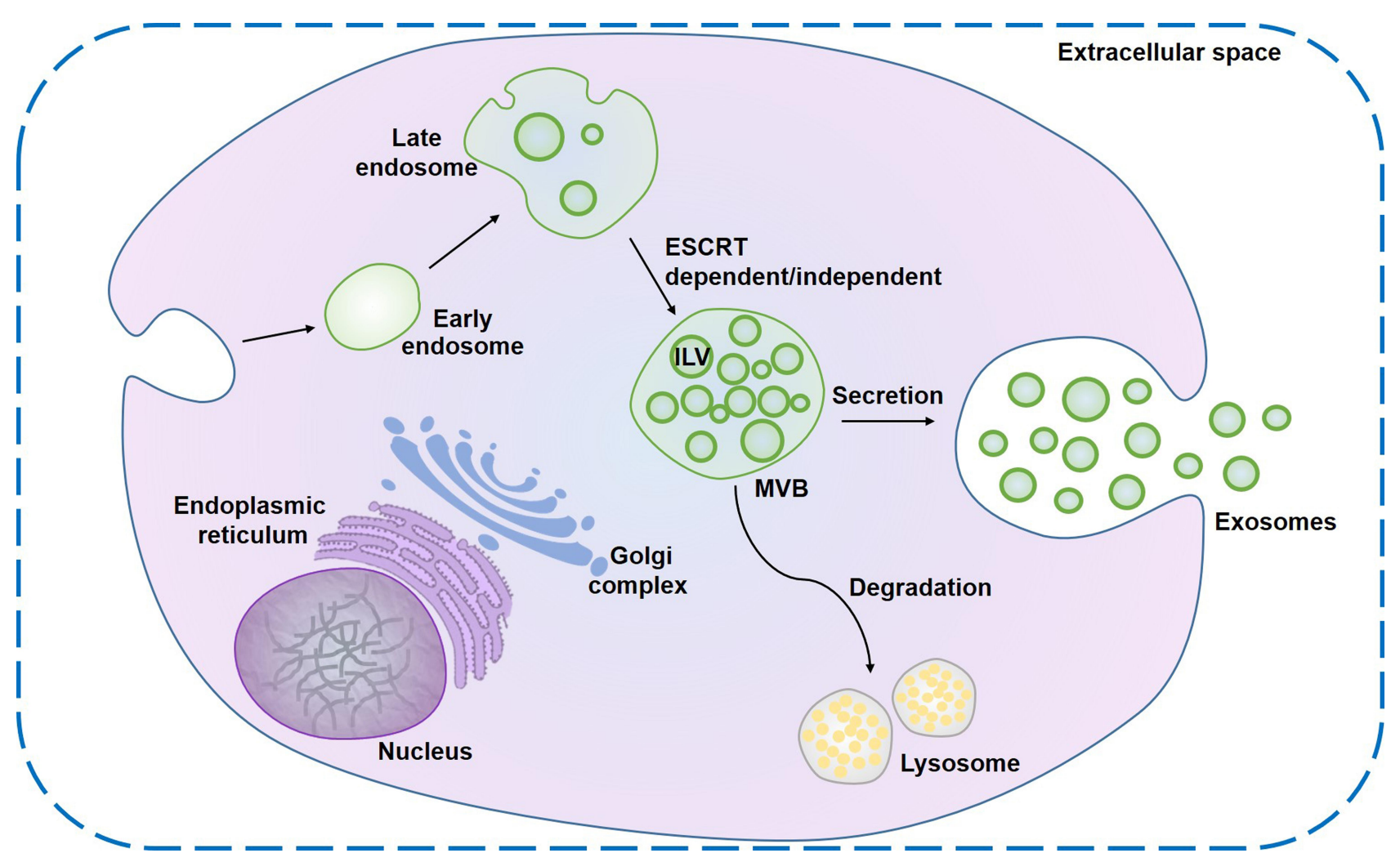

Figure I Biogenesis of exosomes. Exosome formation originates from the early endosomes formed by plasma membrane invagination. The membranes of mature late endosomes buds inward to form ILVs and transform into MVBs. After the MVBs fuse with the plasma membrane, ILVs are released into the extracellular space to form exosomes.

mechanisms exist that contain the endosomal sorting complex required for transport (ESCRT)-dependent mechanisms and ESCRT-independent mechanisms (eg, tetraspanins and lipid-dependent mechanisms) to achieve specific sorting of exosomal contents. ${ }^{38}$ The most well-known mechanism for forming MVB and ILVs is mediated by ESCRT, which is composed of at least twenty proteins that assemble into four complexes (involving ESCRT-0, ESCRT-I, ESCRT-II, and ESCRT-III) with several associated proteins (including VPS4, VTA1, and ALIX) that are highly conserved from yeast to mammals. ${ }^{42,43}$ In addition to ESCRT, some studies have reported that the biogenesis of exosomes is also regulated by other bioactive substances, such as syndecansyntenin-ALIX, ${ }^{44}$ c-Src (a membrane-associated tyrosine kinase), ${ }^{45}$ small GTPase Ral, ${ }^{46}$ Atg12-Atg3 (complex between two core autophagy regulators) ${ }^{47}$ and mixed lineage kinase domain-like (MLKL). ${ }^{48}$

Exosomes with heterogeneous size distribution are observed to be cup-shaped and consist of numerous intracellular components including proteins, nucleic acids (eg, DNAs, mRNAs, and microRNAs), and lipids. These molecules perform different biological functions (Figure 2). ${ }^{13,49}$
The outer membrane of exosomes are basically composed of lipids, interspersed with a variety of membrane proteins. Specific lipids that are abundant in exosomes (eg, cholesterol, phospholipids, and phosphatidylserine) have been investigated. ${ }^{50}$ Undoubtedly, exosomal membrane proteins play an important role in the biological functions of exosomes, such as transmembrane proteins, as well as lipidanchored or peripherally associated membrane proteins. ${ }^{51}$ In addition to various membrane proteins, soluble proteins can exist in the exosome lumen. ${ }^{51,52}$ Interestingly, exosomes of different cellular origin share common protein components. These protein components include tetraspanins that contain CD63, CD9, CD81, and CD82; integrin proteins that take part in cell targeting and adhesion; membrane fusion proteins that are closely related to Rab GTPases, annexins, and flotillin; and several molecular chaperones that mediate the generation of MVBs such as heat shock proteins (HSP) 70 and $90 .{ }^{53}$ Recently, the role of exosomal nucleic acids, RNAs in particular, in cell-tocell communication and genetic exchange between cells have received widespread attention. Research has shown that mRNA and microRNA (miRNA) present in exosomes 


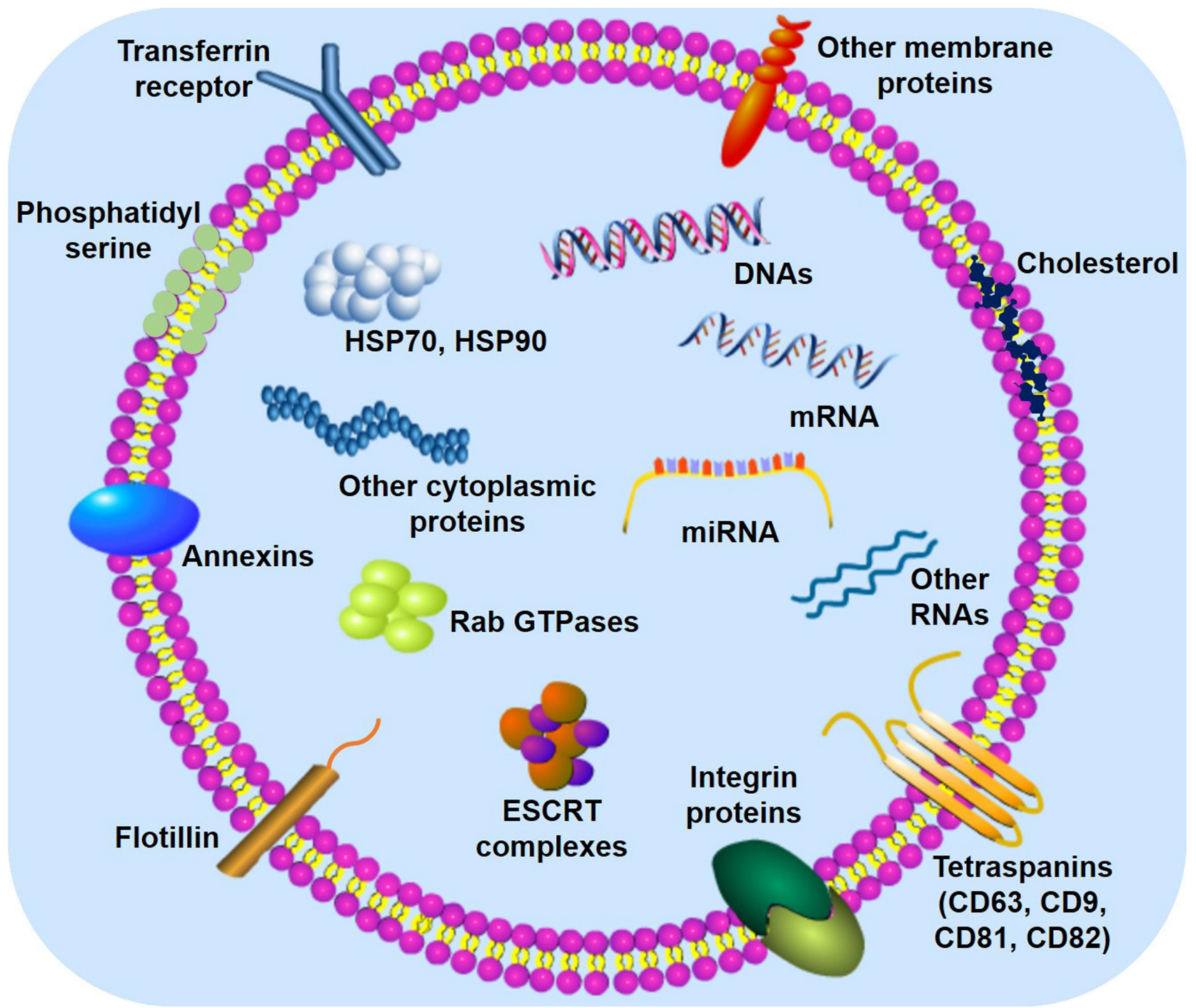

Figure 2 The main components of exosomes. The lipid bilayer of exosomes contains specific lipids such as cholesterol and phosphatidylserine, which can protect the contents from degradation. In addition, various membrane proteins (eg, Tetraspanins, Annexins, Flotillin, and integrin proteins) and intracapsular proteins (eg, HSP70, HSP90, and Rab GTPases) are present in exosomes, each of which assumes different roles. ESCRT (endosomal sorting complex required for transport) is mainly involved in the generation of exosomes. DNA, mRNA, and miRNA are the key genetic materials in exosomes.

mediate their effects by transferring between cells. ${ }^{49,54}$ Furthermore, noncoding RNAs (ncRNAs) such as miRNA, long-ncRNA, and circular RNA are stable in exosomes and play a crucial role in the pathological process of many diseases. ${ }^{55}$

\section{Uptake of Exosomes}

It is well known that cells can communicate with each other by means of exosomes. Exosomes, released from donor cells into the extracellular environment, undergo a free-floating period in which they circulate in body fluids. ${ }^{19}$ Exosomes are ingested by recipient cells in different ways to achieve intercellular communication. Cellular uptake of exosomes can be roughly divided into the following three types: (1) exosomes can fuse directly with the plasma membrane to deliver their cargo to a recipient cell. Although this process is considered to be connected with tetraspanin complexes, a detailed mechanism remains unclear. ${ }^{19,53}$ (2) Exosomes and target cells transmit signals through receptor-ligand interactions. ${ }^{53,56}$ There are soluble signals for the proteolytic cleavage of ligands on the surface of exosomes and juxtacrine signaling for the juxtaposition of ligands and receptors on the exosomes and receptor cells. ${ }^{19}$ (3) Target cells uptake exosomes by diverse forms of endocytosis. These processes of endocytosis include clathrin- and caveolinmediated endocytosis, receptor- and raft-mediated endocytosis, macropinocytosis, and phagocytosis. ${ }^{18,19,57}$ 
Whether exosome selection and uptake by cells is specific is of importance for developing exosome therapies, and several studies, including those on ocular diseases, have reported the response of exosomes from different sources to different cells. For instance, a particular study showed that different receptor cells could non-selectively uptake exosomes from the same cell source, but their uptake capacity and uptake mechanisms were different. ${ }^{58}$ Additionally, Ren et $\mathrm{al}^{59}$ proposed a new drug delivery method for the treatment of neuronal diseases as they found that exosomes isolated from the conditioned medium of bone marrow mesenchymal stem cells (BMSCs) might use retrograde transport to peripheral nerve endings where they were ingested. Notably, some studies have demonstrated the uptake of exosomes from specific ocular cells, which provides a theoretical basis for the clinical application of exosomes in ocular diseases. Interestingly, in vitro, exosomes secreted by human corneal epithelial cells (HCECs) could be taken up by human corneal fibroblasts while HCECs can uptake exosomes released from human mesenchymal stromal cells. ${ }^{60,61}$ Furthermore, in vivo, BMSC-exosomes labeled with green fluorescent protein (GFP) were injected into the vitreous humor and then tracked on retinal ganglion cells (RGCs) together with the retinal nerve fiber layer (RNFL) and resident cells morphologically identified as astrocytes, indicating that these cells could incorporate exosomes. ${ }^{62}$

\section{Methods for Exosome Isolation and Purification}

To date, no technique has been used to isolate exosomes to absolute purity. ${ }^{63}$ Most separation protocols obtain small EVs samples only by removing large EVs without verifying their intracellular origin. ${ }^{16,64}$ With the popularity of the term exosome, many scientists have used exosomes directly to refer to EVs in their publications. ${ }^{65}$ In their isolation protocols, therefore, isolated samples that may contain small EVs are generally referred to directly as exosomes. ${ }^{64}$ Even so, a number of techniques based on the specific traits of exosomes have been developed for the isolation of exosomes from various samples. ${ }^{66}$ These methods, each with its own unique advantages and disadvantages, include differential ultracentrifugation, densitygradient separation, size exclusion chromatography, immunological isolation, and precipitation. In many studies, exosomes have been better isolated by combining different separation methods. ${ }^{63}$ The following are some commonly used separation approaches. Here, we chose to use the term "exosome" to denote samples obtained by various isolation methods.

\section{Differential Ultracentrifugation}

Differential ultracentrifugation is the most common method for isolating exosomes, although it is timeconsuming and carries a significant risk of contamination. ${ }^{67}$ It requires several steps with varying durations and rotation speeds at $4^{\circ} \mathrm{C}$ to obtain exosomes (Figure 3A). ${ }^{68,69}$ Under increasing centrifugal force and rotation speed, larger particles precipitate out in turn, and smaller particles are left in the supernatant. Foreign particles such as dead cells, cell debris, and apoptotic bodies are gradually removed, resulting in the separation of exosomes. $^{70}$

\section{Density-Gradient Separation}

Density-gradient separation can be regarded as the continuation and optimization of differential ultracentrifugation. This technique results in increased purity of exosomes by further separating particles by density and effectively removing other non-exosomes. ${ }^{71}$ At present, sucrose $^{72,73}$ and iodixanol ${ }^{74,75}$ are the two types of density gradient media commonly used in this method. The particular steps to be followed during density-gradient separation are dependent on the type of media chosen (Figure 3B). The physical integrity and bioactivity of exosomes can be better maintained by the cushioning effect of iodixanol and sucrose than by pure ultracentrifugation.

\section{Size Exclusion Chromatography}

Size exclusion chromatography (SEC) is an ideal method to separate exosomes from blood plasma. The technique is low yield but results in no obvious albumin contamination. As such, it has been applied to clinical samples. ${ }^{76,77}$ Unlike the protocol of differential ultracentrifugation, SEC does not rely on ultracentrifugation. ${ }^{78}$ Rather, a solution containing exosomes is run through a stationary phase composed of a porous polymer. Particles larger than the pore size of the polymer are eluted first. Those smaller than the pore size are eluted later, achieving material separation (Figure 3C). ${ }^{79}$

\section{Immunological Isolation}

Recently, highly specific immunoaffinity capture (IAC) technology has been applied to the separation of exosomes. This technique utilizes the immune affinity 
A
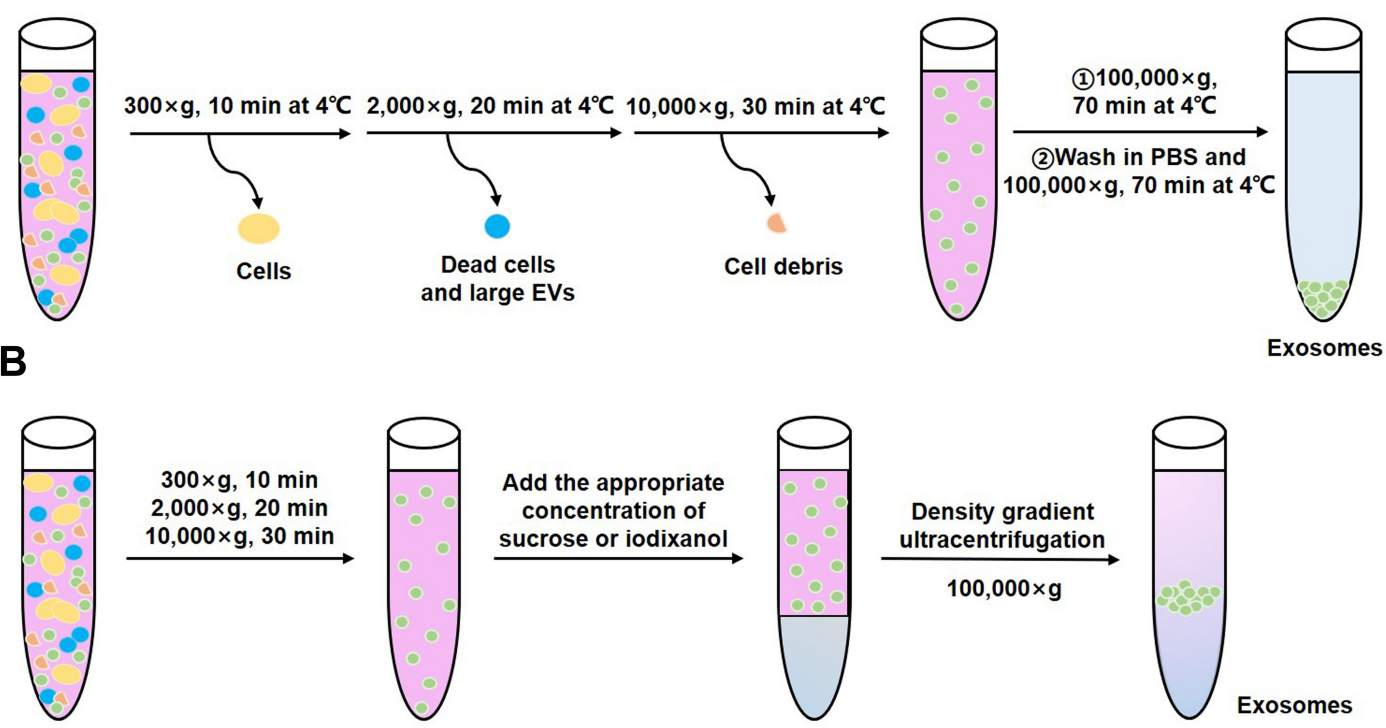

C

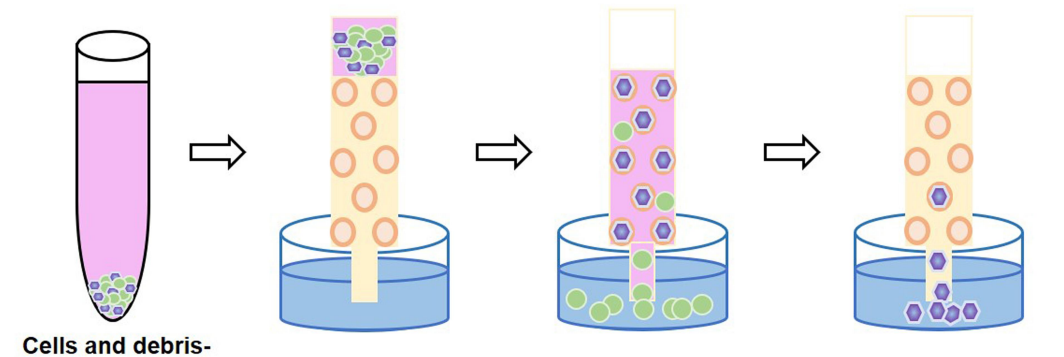

removed samples

Exosomes Protein contaminants

D

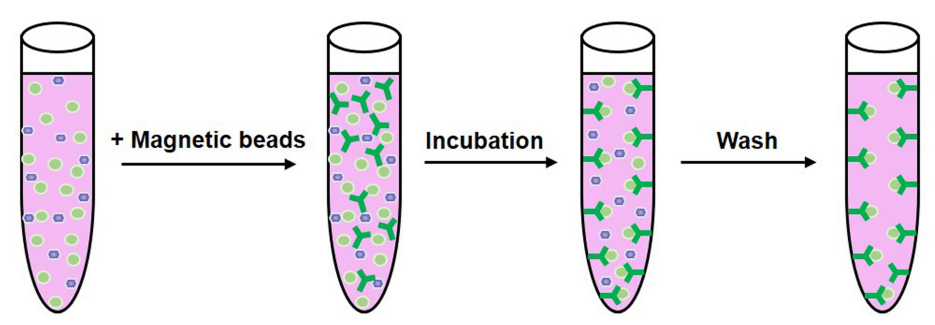

E

Exosomes

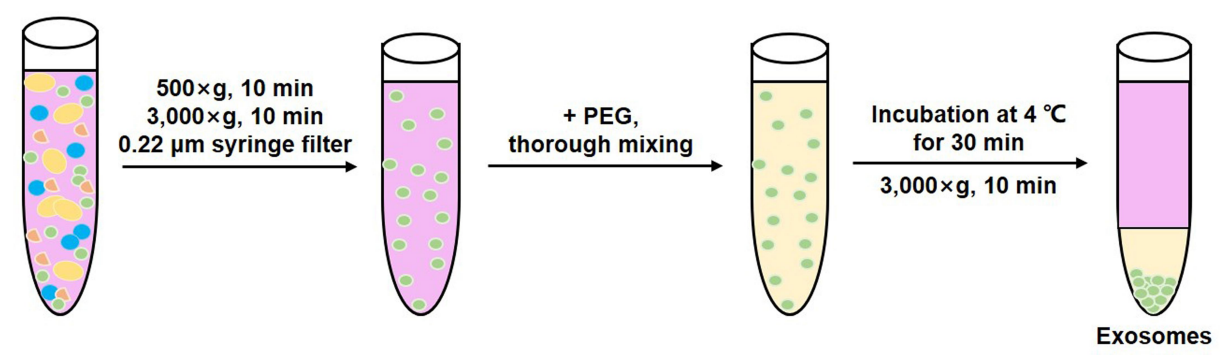

Figure 3 Major methods of exosome isolation. (A) Differential ultracentrifugation (B) Density-gradient separation (C) Size exclusion chromatography (D) Immunological isolation (E) Precipitation. 
interactions between proteins present on the membrane of exosomes and their antibodies. ${ }^{66}$ Magnetic bead-based isolation is a general method for specific capture of exosomes. $^{80}$ Based on the specific surface markers of exosomes, exosomes can be adsorbed and isolated after they are incubated with magnetic beads coated with corresponding antibodies (Figure 3D).

\section{Precipitation}

Precipitation is a simple method of isolation. Biological samples are mixed with a polymer. Exosome precipitation is then achieved at lower speeds of centrifugation (Figure 3E). ${ }^{81}$ Polyethylene glycol (PEG) is a polymer-based precipitation reagent that is commonly used to extract exosomes from cell culture supernatant. PEG has the ability to form exosome aggregates by encapsulating a large quantity of exosomes. ${ }^{82}$

\section{Biological Functions of Exosomes Signal Transduction}

Signal transduction is the most basic and important biological function of exosomes. Early studies reported that exosomes may be cellular garbage carriers to expel metabolic waste in cells. ${ }^{83}$ However, subsequent studies have demonstrated that exosomes can achieve intercellular signaling, thereby regulating various physiological and pathological processes, without the classical pathways of autocrine, paracrine, and direct intercellular contact. Exosomes released from their parent cells can act as vectors of intercellular communication, transporting their contents to adjacent cells or distant cells. They can also transmit information to multiple cells and locations. ${ }^{84}$ Exosomes can serve as a signaling complex by directly binding to receptors on recipient cells and activating those cells. Furthermore, protein fragments, cleaved from the surface of exosomes by proteases, can serve as soluble ligands interacting with surface receptors on target cells to activate associated signaling cascades. ${ }^{85}$ Exosomes can also transfer their cargoes to recipient cells through endocytosis, thus changing the cell status and producing functional effects. ${ }^{86}$ The uptake capacity of exosomes is determined by the type of recipient cell rather than the type of donor cell, which may be closely related to organ-specific metastasis. ${ }^{58}$ Many studies have shown that oxidative stress signals closely related to the processes of various major eye diseases are transferred through exosomes. ${ }^{87,88}$ However, further research is needed to understand the specific cellular and molecular basis for exosomal signal transduction.

\section{Immune Regulation}

The role of exosomes in immunology has been studied extensively. Early studies have found that B lymphocytederived exosomes execute antigen presentation through major histocompatibility complex (MHC) proteins (MHC-I and MHC-II). ${ }^{89}$ Cancer cells, like immune cells, can generate immunologically active exosomes, affecting the immune regulatory mechanism. Exosomes that carry tumor antigens have anti-tumor effects. These exosomes can use $\mathrm{CD}^{+}$and $\mathrm{CD}^{+} \mathrm{T}$ cells to eliminate tumors. They can also directly inhibit the growth and development of tumors. ${ }^{90}$ Kim et al $^{91}$ demonstrated that exosomes secreted from immature dendritic cells (DCs) take part in diminishing inflammatory and autoimmune responses via the MHC-II dependent pathway. A recent study indicated that mesenteric lymph (ML) exosomes released by gut epithelial cells after trauma/hemorrhagic shock (T/HS) may act as key mediators in the induction of post-trauma immune dysfunction, which can markedly increase the expression of MHC-II and Fas ligand. However, ML exosomes may reduce the antigenpresenting capability of DCs that can cause lymphocytes proliferation. $^{92}$

Although the research on the immunomodulatory effect of exosomes is mainly focused on cancer diseases, the immunomodulatory potential of exosomes in ocular diseases has also been investigated in recent years. ${ }^{15,93,94}$ For example, retinal pigment epithelium (RPE) cells can release small EVs under different conditions to inhibit the immune response. Knickelbein et $\mathrm{al}^{95}$ confirmed that EVs from non-stimulated ARPE-19 only suppress the proliferation of $\mathrm{T}$ cells and the immunity of monocytes, but have no effect on cell survival. However, when ARPE-19 cells are stimulated by inflammation-related cytokines, RPE-derived small EVs kill monocytes in addition to inhibiting $\mathrm{T}$ cell proliferation, possibly to mitigate harmful immune responses. More studies further examining the role of exosomes in immune-mediated eye diseases are needed.

\section{Repair Regeneration}

Exosomes contain specific components that play a role in repair and regeneration in a variety of disease models. For example, miRNAs may be essential mediators in the induction of tissue regeneration by the activation or 
inhibition of numerous downstream pathways. ${ }^{96,97}$ Stem cell-derived exosomes are able to induce cardiac angiogenesis and promote postinjury repair by the transfer of specific components (mRNAs, miRNAs, and proteins) into target cells or the site of injury. ${ }^{98}$ In addition, exosomes from mesenchymal stem cells (MSCs) participate in the repair and regeneration of cartilage damage by promoting migration and proliferation, enhancing matrix synthesis, decreasing cell apoptosis, and regulating the immune response. $^{99}$ Existing studies have shown that exosomes also play a key role in liver repair and regeneration. ${ }^{100,101}$ Nojima et al ${ }^{102}$ observed that hepatocyte exosome number increases significantly in the hepatic ischemia-reperfusion model. Hepatocyte exosomes induce hepatocyte proliferation in target cells by transporting enzymes that foster the generation sphingosine-1-phosphate (S1P). Similarly, the ability of exosomes to promote regeneration has been verified in eye diseases models. For example, exosomes within RPE cells subjected to oxidative stress have been shown to exhibit increased levels of mRNAs and proteins specific for the vascular endothelial growth factor receptor (VEGFR). The release of these exosomes results in increased expression of VEGFR-1 and VEGFR-2 and subsequent angiogenic capacity in endothelial cells. $^{103}$

\section{Exosomes as Biomarkers}

Exosomes have a promising potential to serve as biomarkers for a wide range of diseases. The number of exosomes and the specific bioactive substances present in exosomes have been found to vary distinctly between healthy individuals and patients with a variety of diseases. ${ }^{104} \mathrm{Li}$ et al ${ }^{105}$ reported that colon cancer can be identified by the presence of a large number of circRNAs in serum exosomes. Recently, Xiao et al ${ }^{106}$ demonstrated for the first time that cytokeratin 19 (CK19), carbohydrate antigen 125 (CA125), and tumor-associated glycoprotein 72 (TAG72) can be used as biomarkers for colorectal cancer (CRC) due to their different expression levels in exosomes derived from different cells. Moreover, glypican-1 (GPC1) is a proteoglycan exclusively enriched in the surface of cancer exosomes. Melo et $\mathrm{al}^{107}$ reported that healthy people and patients with pancreatic cancer at different stages can be distinguished by $\mathrm{GPC}^{+}$circulating exosomes measured in serum. In addition to exosomal cargo differences, increased levels of exosomes were found in the supernatant of cancer cell cultures and in the blood of cancer patients. ${ }^{108,109}$ An innovative study using small populations found that different types of lipids in exosomes in urine may be specific markers for diagnosing prostate cancer. ${ }^{110}$

As mentioned above, exosomes also exist in bodily fluids closely related to the eye such as aqueous humor $(\mathrm{AH})^{111,112}$ and vitreous humor (VH). ${ }^{113}$ Polarity-specific functions of RPE monolayers can be revealed by directional proteomes of exosomes. ${ }^{114}$ Exosomes isolated from the cultured supernatant of ARPE-19 cells as well as the $\mathrm{AH}$ of patients with age-related macular degeneration (AMD) were identified and compared. ${ }^{115}$ Results indicated that the specific proteins were elevated in the $\mathrm{AH}$ of individuals with AMD subjects. This result provides evidence that exosomal proteins in AH may be used as a biomarker for the diagnosis of AMD. In addition, the basal side of RPE cells, the main lesion site of AMD can release exosomes. These exosomes that enter the blood from the choroid are a potential biomarker for the diagnosis of retinal diseases. ${ }^{116}$ Similarly, the potential of exosomes and their RNA payloads as specific markers in the diagnosis of eye diseases has attracted much attention as of late. Dismuke et al first demonstrated that exosomes are the major EV type in $\mathrm{AH}$ and contain characteristic exosomal RNA, which may provide important basic information for the development of exosomes for the diagnosis of diseases. ${ }^{11}$

\section{Exosomes as Drug Delivery Vesicles}

Exosomes are potential natural drug carriers due their structural composition, diverse biological functions, and unique biological origin. Research has suggested that exosomes could be used to passively and actively deliver drugs with different properties and components. ${ }^{117}$ The efficacy and stability of a drug can be improved by anchoring it to tetraspanins embedded in the exosomal membrane. For example, the attachment of myostatin propeptide to CD63 on the exosomal membrane not only solves the problem of its low stability in serum, but also enhances its inhibitory effect on mature myostatin without toxicity. ${ }^{118} \mathrm{CP} 05$, a peptide of phage display, can increase its efficiency in capturing and loading exosomes and increases the expression of corresponding proteins in muscles by attaching to exosomal CD63 ${ }^{119}$ Furthermore, exosomes facilitate the function of certain bioactive substances by encapsulating them and delivering them to receptor cells. For example, exogenous proteins can be loaded by exosomes and transferred across the bloodbrain barrier to target cells, which may be a promising 
treatment for brain diseases. ${ }^{120}$ Chen et $\mathrm{al}^{121}$ found that endogenous exosomes can independently carry gRNA or Cas9 proteins of the clustered regularly interspaced short palindromic repeats/associated nuclease (CRISPR/Cas) system, thereby transferring the gene editing activity of this system between donor and recipient cells. In addition to the direct effect, autologous exosomes can indirectly promote the delivery of exogenous nanodrugs in vivo and increase the efficacy of drugs. ${ }^{122}$

Because of the limitations of traditional methods for the treatment of eye diseases, increasing attention is being given to exosomes as a medium for drug delivery. Comparison of intravitreal injection of traditional AAV2 with the novel exosome-associated AAV2 (exo-AAV2) revealed that exo-AAV2 carrying the GFP-coding gene adeno-associated virus (AAV) was more strongly expressed and had greater penetrability in the retina. ${ }^{123}$ Additionally, when exosomes from MSCs overexpress miR-126, intravitreal injection can effectively inhibit the signaling pathways associated with inflammatory response in DR. ${ }^{124}$

\section{Toxicity of Exosomes}

Despite increasing research focused on the therapeutic effects of exosomes, little is known about exosomal toxicity. The potential widespread applications of exosomes as therapeutic agents raise concerns about their potential adverse impacts. Exosomes secreted by genetically engineered $\mathrm{T}$ cells whose surfaces bind to chimeric antigen receptor (CAR) have been found to have low toxicity, although they effectively inhibit tumor development. ${ }^{125}$ Recent studies have shown that exosomes contribute to the development of AIDS. HIV-1-infected T cells can not only release exosomes containing the transactivation response (TAR) element RNA to activate the associated cascade and thus aggravate the cancer, but also uninfected cells can produce exosomes to activate latent HIV-1 in infected cells to promote cancer development. ${ }^{126,127}$ In addition, some liver-derived exosomes can cause toxic reactions when applied to target cells. Exogenous exosomes released after acetaminophen liver injury in mice can be absorbed by mouse primary hepatocytes, causing toxicity of receptor cells and induce cell death. ${ }^{128}$ Gao et $\mathrm{al}^{129}$ demonstrated that circulating exosomes loaded with metallothionein 1D pseudogene (MT1DP), released by hepatocytes, target kidney cells to enhance cadmiuminduced nephrotoxicity. Toxic amyloid-beta oligomers can be carried by exosomes from the brain of people with
Alzheimer's disease, allowing these oligomers to move between neurons and worsen the disease. ${ }^{130}$ Zhang et al ${ }^{14}$ have shown that exosomes in serum produced after hepatic ischemia-reperfusion may cause oxidative stress and damage hippocampal and cortical neurons. The eye is an extremely sensitive organ, and with the emergence of exosomes in the study of eye diseases, the toxicity of exosomes on the eyes is a matter of concern that needs to be addressed. However, only a few studies have focused on the adverse effects of exosomes in the eye. Huang et $\mathrm{al}^{131}$ reported that when exosomes are loaded with $\mathrm{IgG}$, they can activate the classical complement pathway, promoting microvascular damage and aggravating DR. However, exosomes lacking Ig-G have the opposite effect. Recently, Ke et $\mathrm{al}^{132}$ extracted exosomes from normal RPE cells and rotenone-induced RPE cells. Compared with the control group, exosomes released by RPE cells under oxidative stress induced inflammation and apoptosis in normal RPE cells through the Apaf1/Caspase-9 signaling pathway. This led to retinal functional damage. Further research into exosomal toxicity in the eye is warranted.

\section{Exosomes and Oxidative Stress}

The concept of oxidative stress was formulated in redox biology and medicine in the 1980s, and it has been studied in a wide range of fields, including chemistry, biology, and pathology. ${ }^{133}$ Oxidative stress is closely linked with a variety of diseases. Subsequently, increased research has focused on the relationship between exosomes and oxidative stress. Plasma exosomes from HIV patients treated with antiretroviral therapies have been reported to be associated with changes in the levels of certain oxidative stress markers, indicating that these exosomes are loaded with oxidative stress-related proteins. ${ }^{134}$ In addition, exosomes and their cargoes may play a role in various diseases by mediating different molecular mechanisms associated with oxidative stress. For example, oxidative stress not only induced more exosomes from cardiac progenitor cells, but it also significantly upregulated miR-21 in exosomes under this condition. Importantly, miR-21 can downregulate its target gene programmed cell death 4 to inhibit oxidative stress-related apoptosis in myocardial cells. ${ }^{135}$ Saeed-Zidane et $\mathrm{al}^{136}$ found that exosomes, secreted by bovine granulosa cells under oxidative stress, contained abundant Nrf2 mRNA and possible antioxidants, which may mediate the molecular defense mechanism related to oxidative stress in granulosa cells. Similarly, oxidative stress plays an important role in many ocular 
diseases, such as diabetic retinopathy and age-related macular degeneration. ${ }^{137-139}$ There is no doubt that the role of exosomes released by eye cells exposed to oxidative stress is worthy of considerable attention.

\section{Exosomes in Diseased Eyes}

Exosomes contain proteins, lipids, and nucleic acids that are associated with their parental cells and thus have a wide range of biological functions. The following is an introduction to their functions in eye diseases (Table 1).

\section{Diabetic Retinopathy}

Diabetic retinopathy (DR), one of the serious complications of diabetes, is the most important manifestation of diabetic microangiopathy, resulting in a fundus lesion with specific changes. The main pathological stages of DR include non-proliferative DR, pre-proliferative DR, and proliferative DR. Diabetic macular oedema, characterized by vascular leakage and macula, is a special subtype of non-proliferative of DR. ${ }^{140,141}$ The pre-proliferative stage refers to capillary closures and the existence of a nonperfusion area. The development of neovascularization is a marker of proliferative DR, and hypoxia plays an important role in this stage. ${ }^{141}$ Obviously, retinal ischemiareperfusion injury (IRI) to a large extent mediates the pathological process of DR. ${ }^{142}$ Retinal ischemia directly leads to temporary hypoxia and the loss of important nutrients. Reperfusion then promotes the production of excessive reactive oxygen species (ROS) inducing oxidative stress and further inflammatory responses. ${ }^{143}$ Finally, IRI causes necrosis, apoptosis, and autophagy resulting in a decrease in retinal neurons, especially RGCs. ${ }^{144}$

The role of exosomes secreted by MSCs in the eye is coming into focus as studies confirm that DR can be improved after intravitreal injection of MSC derived exosomes. ${ }^{124}$ Moisseiev et al ${ }^{145}$ demonstrated the effect of exosomes on retinal ischemia by intravitreal injection of hypoxia-cultured exosomes containing angiogenic active ingredients from human-MSCs (hMSCs) and control saline in oxygen-induced retinopathy (OIR) mouse models. Compared with the control group, exosome treatment inhibited retinal thinning and alleviated retinal ischemia. Studies have also been conducted on the role of exosomes in diabetic microangiopathy. EVs in plasma of diabetic patients with retinopathy were found to increase the expression of cytokines and angiogenic factors, suggesting that these EVs may be involved in the transmission of carrier-related factors. ${ }^{146}$ Recently, Maisto et $\mathrm{al}^{147}$ used high concentrations of glucose to stimulate retinal photoreceptors to simulate DR. They found that high glucose levels increased vascular endothelial growth factor (VEGF) and diminished anti-angiogenic miRNA levels in photoreceptors and exosomes. A study on diabetic microvascular complications found that exosomes can carry circular RNAs-cPWWP2A, an endogenous miR-579 sponge, and indirectly mediate the function of retinal vessels in patients with diabetes through different expression levels of cPWWP2A and miR-579. ${ }^{148}$ However, it has been found that the level of platelet-rich plasma exosomes is significantly increased in the plasma of diabetic rats, which can up-regulate the TLR4 signaling pathway that regulates inflammatory response and can cause retinal endothelial injury. ${ }^{149}$ Kamalden et $\mathrm{al}^{150}$ confirmed that miR-15a, delivered by circulating exosomes after pancreatic production, can cause oxidative stress to enhance type2-diabetes (T2D)-induced DR. PPAR $\gamma$ is an active ingredient in exosomes. Katome et $\mathrm{al}^{151}$ showed that PPAR $\gamma$ was significantly increased in $\mathrm{AH}$ and $\mathrm{VH}$ of patients with proliferative DR, revealing that exosomes play an important role in DR.

\section{Age-Related Macular Degeneration}

The retina is a soft transparent membrane that is sensitive to light stimulation and is attached to the inner surface of the choroid through the outermost layer of RPE and the Burch membrane. ${ }^{152}$ The RPE is composed of monolayer pigment epithelial cells, which are vulnerable to oxidative stress, especially ROS, due to their anatomical position and function. ${ }^{103}$

Age-related macular degeneration (AMD), which occurs mostly in people over 50 years of age, is the leading cause of blindness among the elderly in developed countries. According to the clinical manifestations and pathological changes, it is divided into dry AMD and wet AMD. Wet AMD, also known as neovascular AMD, is characterized by the occurrence of choroidal neovascularization (CNV) and accompanied by choroidal and retinal hemorrhage. Wet AMD produces more serious visual impairment than dry AMD. Neovascularization does not occur in dry AMD, but yellow drusen form underneath the RPE. Dry AMD is accompanied by geographical atrophy, also known as atrophic AMD. ${ }^{153}$

RPE, which forms the outer blood-retina barrier (BRB), plays an important role in the pathogenesis of AMD. It has been reported that oxidative stress, an important factor leading to AMD, can cause donor cells to 
Table I. A Brief Description of the Biological Role of Exosomes in Related Eye Diseases

\begin{tabular}{|c|c|c|c|c|}
\hline $\begin{array}{l}\text { Related Eye } \\
\text { Diseases }\end{array}$ & Origin of Exosomes & Exosomal Content & Biological Function of Eye Diseases & References \\
\hline $\begin{array}{l}\text { Diabetic } \\
\text { retinopathy } \\
\text { (DR) }\end{array}$ & $\begin{array}{l}\text { Human umbilical cord- } \\
\text { derived mesenchymal stem } \\
\text { cells (MSCs) }\end{array}$ & miR-126 & $\begin{array}{l}\text { Alleviates hyperglycemia-induced retinal } \\
\text { inflammation by inhibiting the HMGBI } \\
\text { signaling pathway }\end{array}$ & 124 \\
\hline DR & Plasma from diabetic mice & $\lg -\mathrm{G}$ & $\begin{array}{l}\text { Activates the classical complement pathway } \\
\text { via Ig-G to aggravate the development of } D R\end{array}$ & 131 \\
\hline DR & $\begin{array}{l}\text { Human MSCs cultured } \\
\text { under hypoxic conditions }\end{array}$ & & $\begin{array}{l}\text { Reduces the severity of retinal ischemia in } \\
\text { murine model }\end{array}$ & 145 \\
\hline DR & Retinal photoreceptors & miRNAs, VEGF & Mediates the regulation of angiogenesis & 147 \\
\hline DR & Platelet-rich plasma & CXCLIO & $\begin{array}{l}\text { Upregulates the TLR4 signaling pathway to } \\
\text { mediate hyperglycemia-induced retinal } \\
\text { endothelial injury }\end{array}$ & 149 \\
\hline DR & Pancreatic- $\beta$-cells & miR-15a & $\begin{array}{l}\text { Transfers miR-15a from the pancreas into } \\
\text { retinal cells to enhance diabetic } \\
\text { complications }\end{array}$ & 150 \\
\hline DR & Plasma & $\begin{array}{l}\text { peroxisome proliferator-activated } \\
\text { receptor gamma (PPAR } \gamma)\end{array}$ & $\begin{array}{l}\text { Loads PPAR } \gamma \text {, participates in the } \\
\text { pathogenesis of proliferative DR }\end{array}$ & 151 \\
\hline $\begin{array}{l}\text { Age-related } \\
\text { macular } \\
\text { degeneration } \\
\text { (AMD) }\end{array}$ & $\begin{array}{l}\text { Human retinal pigment } \\
\text { epithelial ARPE-19 cells; } \\
\text { aqueous humor }(\mathrm{AH})\end{array}$ & $\begin{array}{l}\text { Cytokeratin 8, cytokeratin } 14 \text {, } \\
\text { cathepsin D, Hsp70; myosin-9, } \\
\text { and actin, aortic smooth muscle }\end{array}$ & $\begin{array}{l}\text { Has the potential to diagnose neovascular } \\
\text { AMD as novel biomarkers }\end{array}$ & 115 \\
\hline AMD & $\begin{array}{l}\text { Retinal astroglial cells } \\
\text { (RACs) }\end{array}$ & $\begin{array}{l}\text { Multiple antiangiogenic } \\
\text { components }\end{array}$ & $\begin{array}{l}\text { Suppresses laser-induced choroidal } \\
\text { neovascularization }\end{array}$ & 155 \\
\hline AMD & ARPE-19 cells & VEGFR2 & Involved in new blood vessel formation & 156 \\
\hline AMD & $\begin{array}{l}\text { Retinal pigment epithelial } \\
\text { (RPE) cells }\end{array}$ & & $\begin{array}{l}\text { Transports and releases anti-VEGF antibody } \\
\text { bevacizumab as drug delivery vesicles }\end{array}$ & 158 \\
\hline AMD & Serum & $\begin{array}{l}\text { miR-486-5p, miR-626, miR-885- } \\
5 p\end{array}$ & $\begin{array}{l}\text { Has the potential to diagnose wet AMD as } \\
\text { novel biomarkers by these circulating } \\
\text { microRNAs }\end{array}$ & 159 \\
\hline AMD & $\begin{array}{l}\text { Cultured ARPE-19 cells } \\
\text { under oxidative stress } \\
\text { conditions }\end{array}$ & Signaling phosphoproteins & $\begin{array}{l}\text { Has the potential to mediate cell-cell } \\
\text { signaling during physio-pathological and act as } \\
\text { biomarkers }\end{array}$ & 160 \\
\hline $\begin{array}{l}\text { Autoimmune } \\
\text { uveitis }(A U)\end{array}$ & Human MSCs & & $\begin{array}{l}\text { Ameliorates experimental } \mathrm{AU} \text { through } \\
\text { suppressing the migration of inflammatory } \\
\text { cells }\end{array}$ & 161 \\
\hline$A U$ & MSCs & & $\begin{array}{l}\text { Protects the retinal structure of } \\
\text { experimental } A U \text { rat model and reduces } \\
\text { inflammatory cell infiltration }\end{array}$ & 162 \\
\hline $\begin{array}{l}\text { Primary open- } \\
\text { angle glaucoma } \\
\text { (POAG) }\end{array}$ & $\begin{array}{l}\text { Non-pigmented ciliary } \\
\text { epithelium (NPCE) } \\
\text { primary cells }\end{array}$ & miR-29b & Reduces levels of WNT/ $\beta$-catenin pathway & 169 \\
\hline
\end{tabular}


Table I. (Continued).

\begin{tabular}{|c|c|c|c|c|}
\hline $\begin{array}{l}\text { Related Eye } \\
\text { Diseases }\end{array}$ & Origin of Exosomes & Exosomal Content & Biological Function of Eye Diseases & References \\
\hline POAG & $\begin{array}{l}\text { Primary human trabecular } \\
\text { meshwork (TM) cells }\end{array}$ & miR-182 & Associated with POAG via miR-182 & 170 \\
\hline Glaucoma & Cultured NPCE cells & & $\begin{array}{l}\text { Involved in signaling between the } \mathrm{AH} \text { forming } \\
\text { and draining cells in the ocular system }\end{array}$ & 112 \\
\hline Glaucoma & $\begin{array}{l}\text { Bone marrow MSCs } \\
\text { (BMSC) }\end{array}$ & & $\begin{array}{l}\text { Promotes neuroprotection by preserving the } \\
\text { level of RGCs and protecting against axonal } \\
\text { degeneration }\end{array}$ & 62 \\
\hline $\begin{array}{l}\text { Optic nerve } \\
\text { crush (ONC) }\end{array}$ & BMSC & & $\begin{array}{l}\text { Promotes the survival of Retinal Ganglion } \\
\text { Cells (RGCs) and the regeneration of their } \\
\text { axons by miRNA-dependent pathway }\end{array}$ & 173 \\
\hline ONC & Umbilical cord MSCs & & $\begin{array}{l}\text { Promotes the survival of RGCs and activates } \\
\text { glia cells for neuroprotection }\end{array}$ & 174 \\
\hline $\begin{array}{l}\text { Corneal } \\
\text { diseases }\end{array}$ & Corneal fibroblasts & $\begin{array}{l}\text { Matrix metalloproteinase (MMP) } \\
14\end{array}$ & $\begin{array}{l}\text { Mediates corneal angiogenesis via exosomal } \\
\text { MMPI4 transport }\end{array}$ & 176 \\
\hline $\begin{array}{l}\text { Corneal } \\
\text { diseases }\end{array}$ & $\begin{array}{l}\text { Human Corneal } \\
\text { Mesenchymal Stromal } \\
\text { Cells }\end{array}$ & & $\begin{array}{l}\text { Treats ocular surface injuries by accelerating } \\
\text { corneal epithelial wound healing }\end{array}$ & 61 \\
\hline $\begin{array}{l}\text { Retinopathy of } \\
\text { prematurity } \\
\text { (ROP) }\end{array}$ & Microglial cells & miR-24-3p & $\begin{array}{l}\text { Attenuates photoreceptor injury and } \\
\text { neovascularization of ROP model }\end{array}$ & 181 \\
\hline $\begin{array}{l}\text { Uveal } \\
\text { melanoma } \\
\text { (UM) }\end{array}$ & Melanoma & microRNA & $\begin{array}{l}\text { Provides theoretical basis for the diagnosis of } \\
\text { exosomes in metastatic UM }\end{array}$ & 187 \\
\hline
\end{tabular}

secrete EVs that transmit stress signals to normal RPE cells to weaken the barrier function of RPE. ${ }^{154}$ Many types of retinal cells can generate and release exosomes, such as RPE cells and retinal astroglial cells (RACs), which may be involved in the pathological process of AMD. However, the roles of these different cell-derived exosomes in the retina are also markedly different. Hajrasouliha et al ${ }^{155}$ demonstrated that RACs-derived exosomes contain anti-angiogenic components that can reduce retinal vascular leakage and curb CNV. These results suggest a new treatment of AMD. Exosomes from RPE cells, however, do not have this capability. Interestingly, unlike healthy RPE cells, RPE cells under stress release large amounts of exosomes containing VEGFR2 that enhance the formation of new blood vessels. In addition, exosomes from RPE cells under stress increase autophagy to promote AMD. ${ }^{156}$ Moreover, Wang et al ${ }^{157}$ conjectured that exosomes and autophagy might mediate and enhance the formation of drusen during AMD. Bevacizumab, an antiVEGF antibody against AMD, has also been found to be taken up by RPE cells after intravitreal injection and then re-released by exosomes. ${ }^{158}$

Numerous studies have revealed that exosomes contain cargo that may serve as biomarkers for the diagnosis of AMD, particularly microRNA and proteins. For instance, Kang et $\mathrm{al}^{115}$ indicated that exosome proteins have great potential as novel biomarkers for the diagnosis of neovascular AMD as they found changes in exosomal proteins levels in the AH of subjects with AMD. A recent study found that the expression of three new circulating microRNAs, including miR-486-5p, miR-626, and miR$885-5 \mathrm{p}$, significantly differed in control and individuals with AMD, but their effects were not identical. The results showed that the expression of miR-486-5p and miR-626 were up-regulated in patients, while the expression of miR-885-5p was down-regulated in patients. ${ }^{159}$ In 
addition, Biasutto et al $^{160}$ used reverse phase protein arrays analysis to find that the content of some phosphoproteins in cultured ARPE-19 cells-derived exosomes subjected to oxidative stress were changed, suggesting that these exosomal proteins may be involved in cell apoptosis and cell metabolism. All of the above studies provide theoretical and experimental basis for exosomes to be used as specific markers in the diagnosis of AMD.

\section{Autoimmune Uveitis}

Uveitis is the general name for inflammation of iris, ciliary body, and choroidal. According to the location, the disease can be divided into anterior uveitis, posterior uveitis middle uveitis, and panuveitis. Autoimmune uveitis (AU) involves not only inflammation of the uveitis itself, but also inflammation of adjacent tissues such as the retina and vitreous. RPE cells, which have immunosuppressive properties, may modulate the immune response by releasing exosomes. ${ }^{15}$ In recent years, the role of exosomes in autoimmune uveitis has been studied.

Studies have shown that MSCs used in the treatment of eye diseases have a significant immunomodulatory effect and can repair damaged or diseased tissues and organs. Previous studies have demonstrated that MSCs can improve experimental $\mathrm{AU}$ in rat models. Based on the relevant experiments of MSCs, Bai et $\mathrm{al}^{161}$ verified the role of exosomes secreted by MSCs in the experimental AU rat model through periocular injection. They found that periocular injection of hMSCs-derived exosomes reduced leukocyte infiltration in the eyes and alleviated uveitis. These results suggest that exosomes from hMSCs have promising potential in the treatment of AU. Interestingly, the MSC exosomes were found to regulate the immune response by inhibiting the flow of inflammatory cells into the eye rather than by inhibiting the specific immune response of $\mathrm{T}$ cells. In addition, a study has shown that intravenous administration of exosomes released by MSCs immediately after immunization can protect the retinal structure of experimental AU rat model and reduce inflammatory cell infiltration. These results are similar to those found with injection of MSC exosomes around the eye. $^{162}$

\section{Glaucoma and Traumatic Optic Neuropathies}

Glaucoma is a group of diseases characterized by atrophy and depression of the optic nerve, visual field defects, and visual decline. Pathologically increased intraocular pressure (IOP) and insufficient blood supply to the optic nerve are the primary risk factors for glaucoma. The tolerance of the optic nerve to pressure damage is also related to the occurrence and development of glaucoma. There are two subtypes of glaucoma: open-angle glaucoma and closedangle glaucoma. The two subtypes can be further divided into primary and secondary glaucoma. ${ }^{163}$ Patients with primary glaucoma have normal or elevated IOP, but no clear cause has been identified. ${ }^{163-165}$ In addition, normal tension glaucoma, with no increase in IOP, is considered likely to be a singular subtype of primary open-angle glaucoma (POAG). ${ }^{166}$ Unlike primary glaucoma, secondary glaucoma has identifiable causes, such as elevated IOP. ${ }^{163,164}$ During the development of glaucoma, the RGCs are gradually lost due to the increased IOP caused by the increased generation and reduced outflow of $\mathrm{AH},{ }^{167}$ which hinders the transmission of information from the retina to the brain. Therefore, reducing intraocular pressure and decreasing the loss of RGCs are the main methods of glaucoma treatment. Trabecular meshwork (TM) that can drain $\mathrm{AH}$ to reduce IOP is the main objective of clinical treatment. ${ }^{168}$

Lerner et al $^{169}$ performed protein analysis on exosomes secreted by primary cells of the non-pigmented ciliary epithelium (NPCE) and a NPCE cell line. They found that these exosomes contained a large number of negative modulators of Wnt signaling miR-29b. After treating TM cells with these exosome samples, the expression of COL3A1 was down-regulated, suggesting that NPCE cells-derived EVs may mediate the regulation of TM classical Wnt signaling. Lerner et al $^{170}$ also reported that exosomes derived from NPCE cells are involved in the regulation of Wnt signaling proteins in TM cells, suggesting that EVs are involved in signal communication between related cells in the ocular water system. A study reported by Liu et al ${ }^{171}$ suggested the potential role of exosomes in POAG. They conducted a large-scale study of TM gene expression in patients with POAG and healthy subjects, and for the first time demonstrated that TM gene expression occurred in patients with a Q368X myocilin mutation. It is worth noting that flotillin-2 and tetraspanin-6, two exosome-enriched proteins, had different TM gene expression in POAG patients. Moreover, exosome-related proteins, including matrix GLA protein, SPARC, and TIMP2, are expressed by a few TM characteristic genes that were different in non-myocilin POAG individuals. $^{171,172}$ One study used miRNA sequencing (miRNA-Seq) to detect the expression of miR-182 in various 
types of human eye tissues, human $\mathrm{AH}$, and exosomes derived from human primary TM cells, respectively, to verify the correlation between miRNA variation and POAG. ${ }^{112} \mathrm{In}$ addition to studies on TM, the therapeutic effect of MSCderived exosomes from different tissues on glaucoma and traumatic optic neuropathies has been extensively investigated. For example, a series of tests were carried out after weekly intravitreal injection of exosomes released by bone marrow-derived MSCs (BMSCs) in rats of the optic nerve crush (ONC) model. Exosomes from BMSCs were found to enhance the survival of RGCs and promote axonal regeneration, thus significantly protecting the optic nerve. ${ }^{62}$ This neuroprotective effect of BMSC-derived exosomes has also been demonstrated in the genetic DBA/2J mouse model of glaucoma. ${ }^{173}$ However, Pan et al ${ }^{174}$ investigated the effect of exosomes released by umbilical cord MSCs on ONC rats and found that cell-derived exosomes increased the survival of RGCs but did not promote axonal regeneration.

\section{Corneal Disease}

Corneal disease, one of the primary eye diseases leading to blindness, causes the clear cornea to appear pale and opaque, which can lead to blurred vision, decreased vision, and even blindness. Corneal defects in mice with mucopolysaccharidosis VII have been found to be repaired by human umbilical cord MSC transplantation. ${ }^{175}$ Han et al ${ }^{176}$ isolated exosomes containing matrix metalloproteinase (MMP) 14 from corneal fibroblasts. MMP14, an angiogenic enzyme, is transported by corneal fibroblast exosomes to vascular endothelial cells to promote corneal angiogenesis. In addition, MMP14 is involved in the recruitment of its target MMP2 on corneal fibroblast exosomes. Samaeekia et $\mathrm{al}^{61}$ extracted exosomes from the secretome of human corneal mesenchymal stromal cells by differential ultracentrifugation and conducted in vitro and in vivo experiments. Compared with a control group, both the remaining wound area in an in vitro scratch assay and the degree of wounds in in vivo corneal epithelial debridement wounds in mice were significantly improved by these exosomes. The results suggest that human corneal mesenchymal stromal cells exosomes may be used to treat corneal epithelial trauma. More recently, one study has shown that the treatment of HCEC-derived EVs increased myofibroblast differentiation via the expression of $\alpha$-smooth muscle actin and the elevation of contractility, suggesting that these EVs may conduct corneal scarring. ${ }^{60}$

\section{Retinopathy of Prematurity}

The data shows that there are different causes of childhood blindness in different regions of the world, and retinopathy of prematurity (ROP) is one of the leading causes of childhood blindness in the United States. ${ }^{177}$ Infants born before term (40 weeks) are prone to various lesions because their tissues and organs, especially those related to the visual system, are not fully developed. ROP, clinically characterized by retinal vasculature abnormalities, is a clinical entity involving the retina. ${ }^{178,179}$ ROP consists of two oxygen-dependent postpartum phases: Phase 1, characterized by the arrest of vascular growth, and Phase 2, characterized by vascular proliferation. ${ }^{180}$

In phase 1, hyperoxia, which inhibits VEGF, is an important inducer of this disease. Importantly, normal air conditions can also lead to hyperoxia in addition to oxygen therapy to increase infant survival. ${ }^{180}$ As a baby grows, the increased metabolism changes the retina from a hyperoxic state to a hypoxic state, and the disease enters phase 2. In contrast, this stage promotes VEGF. ${ }^{180}$ One study showed that exosomes from MSCs could effectively improve hyperoxia-induced retinopathy, and that exosomes were well tolerated after intravitreal injection, providing a novel idea for safe non-cellular therapy for ROP. ${ }^{145}$ Of note, $\mathrm{Xu}$ et al ${ }^{181}$ investigated the role of exosomes derived from microglia in an animal model of ROP. Recently, the idea that microglia cells are involved in the formation and development of the central nervous system has emerged, ${ }^{182}$ and a recent study has found that microglia may improve retina-related diseases. ${ }^{183}$ Microglia-derived exosomes were injected into the vitreous body of a mouse model and showed a series of manifestations: 1) reduction of avascular areas and neovascular tufts; 2) decreased expression of VEGF and transforming growth factor $\beta$ (TGF- $\beta$ ), and 3 ) inhibition of photoreceptor apoptosis. ${ }^{181}$ These findings also provide a theoretical basis for exosomes to be used as a new treatment method for ROP. Indeed, the efficacy of exosomes in ROP remains to be further studied.

\section{Uveal Melanoma}

Although eye cancer is rare, it can be devastating when it occurs. Uveal melanoma (UM) is a common cancer of the eye. ${ }^{184} \mathrm{UM}$, a primary intraocular malignancy, is a general term for melanoma of the choroid, ciliary body, or iris. ${ }^{185}$ Notably, nearly half of patients with UM have organ metastases, especially liver metastases. ${ }^{186}$ Eldh et $\mathrm{al}^{187}$ extracted exosomes from liver perfusate from patients 
with hepatic metastatic UM who underwent hepatic perfusion. In metastatic UM, exosomes originating from melanoma are released for hepatic circulation, and these exosomes contain Melan-A and melanoma-related microRNAs, thus further demonstrating their origin. More importantly, exosomes can be isolated from local blood circulation in patients with metastatic UM, and their RNA clusters are specific. ${ }^{187}$ Similarly, miRNA profiles from vitreous exosomes from patients with UM were analyzed in another study, which also suggested that exosomal RNAs may be potential specific markers for diagnosing UM. ${ }^{188}$ Thus, exosomes have not been well studied in UM, but their potential and prospects in the diagnosis of disease are worth exploring.

\section{Conclusions and Future Perspectives}

Current evidence has shown that exosomes contain a variety of proteins and genetic material that contribute to their broad biological functions including information transmission, immune regulation, repair, and regeneration. As discussed in this review, a number of studies provide evidence for the important role played by exosomes in the pathological process of ocular diseases, including inflammation, neuronal degeneration, oxidative stress, and neovascularization. In addition, exosomes have the ability to cross biological barriers. Using exosomes as biomarkers or therapeutic carriers may bring better and personalized treatment to patients with eye diseases. Taken together, this review advances the understanding of the role of exosomes in ocular diseases. However, based on the complexity and diversity of exosomes, the functions and mechanisms of exosomes in ocular diseases requires further investigation. The role of exosomes as biomarkers or therapeutic vehicles in ocular disease diagnosis and clinical treatments needs further study. Moreover, there is no established standard for separating and purifying exosomes, let alone the mass production of exosomes, which needs urgently require research. Therefore, significant studies are needed to develop such therapeutic treatments in ocular diseases.

\section{Acknowledgments}

This work was supported by the National Natural Science Foundation of China (81970826) to Zhuhong Zhang, Talent Induction Program for Youth Innovation Teams in Colleges and University of Shandong Province to Yanping
Zhu, and National Natural Science Foundation of China (81800853) to Feng Jiang.

\section{Disclosure}

The authors report no conflicts of interest for this work.

\section{References}

1. Mathieu M, Martin-Jaular L, Lavieu G, Thery C. Specificities of secretion and uptake of exosomes and other extracellular vesicles for cell-to-cell communication. Nat Cell Biol. 2019;21(1):9-17. doi:10.1038/s41556-018-0250-9

2. Hessvik NP, Llorente A. Current knowledge on exosome biogenesis and release. Cell Mol Life Sci. 2018;75(2):193-208. doi:10.1007/s00018-017-2595-9

3. Pan BT, Johnstone RM. Fate of the transferrin receptor during maturation of sheep reticulocytes in vitro: selective externalization of the receptor. Cell. 1983;33(3):967-978. doi:10.1016/00928674(83)90040-5

4. Pan BT, Teng K, Wu C, Adam M, Johnstone RM. Electron microscopic evidence for externalization of the transferrin receptor in vesicular form in sheep reticulocytes. $J$ Cell Biol. 1985;101 (3):942-948. doi:10.1083/jcb.101.3.942

5. Johnstone RM, Adam M, Hammond JR, Orr L, Turbide C. Vesicle formation during reticulocyte maturation. Association of plasma membrane activities with released vesicles (exosomes). J Biol Chem. 1987;262(19):9412-9420.

6. Yu B, Zhang X, Li X. Exosomes derived from mesenchymal stem cells. Int J Mol Sci. 2014;15(3):4142-4157. doi:10.3390/ijms150 34142

7. Mueller SK, Nocera AL, Bleier BS. Exosome function in aerodigestive mucosa. Nanomedicine. 2018;14(2):269-277. doi:10.10 16/j.nano.2017.10.008

8. Colombo M, Raposo G, Thery C. Biogenesis, secretion, and intercellular interactions of exosomes and other extracellular vesicles. Annu Rev Cell Dev Biol. 2014;30:255-289. doi:10.11 46/annurev-cellbio-101512-122326

9. Li S, Li Y, Chen B, et al. exoRBase: a database of circRNA, lncRNA and mRNA in human blood exosomes. Nucleic Acids Res. 2018;46(D1):D106-D112. doi:10.1093/nar/gkx891

10. Klingeborn M, Dismuke WM, Bowes Rickman C, Stamer WD. Roles of exosomes in the normal and diseased eye. Prog Retin Eye Res. 2017;59:158-177. doi:10.1016/j.preteyeres.2017.04.004

11. Kang X, Zuo Z, Hong W, Tang H, Geng W. Progress of research on exosomes in the protection against ischemic brain injury. Front Neurosci. 2019;13:1149. doi:10.3389/fnins.2019.01149

12. Yamashita T, Takahashi Y, Takakura Y. Possibility of exosome-based therapeutics and challenges in production of exosomes eligible for therapeutic application. Biol Pharm Bull. 2018;41(6):835-842. doi:10.1248/bpb.b18-00133

13. Akbari A, Jabbari N, Sharifi R, et al. Free and hydrogel encapsulated exosome-based therapies in regenerative medicine. Life Sci. 2020. doi:10.1016/j.lfs.2020.117447

14. Zhang L, Liu H, Jia L, et al. Exosomes mediate hippocampal and cortical neuronal injury induced by hepatic ischemia-reperfusion injury through activating pyroptosis in rats. Oxid Med Cell Longev. 2019;2019:1-17. doi:10.1155/2019/3753485

15. Li N, Zhao L, Wei Y, Ea VL, Nian H, Wei R. Recent advances of exosomes in immune-mediated eye diseases. Stem Cell Res Ther. 2019;10(1):278. doi:10.1186/s13287-019-1372-0

16. Tkach M, Thery C. Communication by extracellular vesicles: where we are and where we need to go. Cell. 2016;164 (6):1226-1232. doi:10.1016/j.cell.2016.01.043 
17. Edgar JR. Q\&A: what are exosomes, exactly? BMC Biol. 2016;14:46. doi:10.1186/s12915-016-0268-z

18. Mulcahy LA, Pink RC, Carter DR. Routes and mechanisms of extracellular vesicle uptake. J Extracell Vesicles. 2014;3doi. 10.3402/jev.v3.24641.

19. McKelvey KJ, Powell KL, Ashton AW, Morris JM, McCracken SA. Exosomes: mechanisms of uptake. J Circ Biomark. 2015;4:7. doi:10.5772/61186

20. Nedaeinia R, Manian M, Jazayeri M, et al. Circulating exosomes and exosomal microRNAs as biomarkers in gastrointestinal cancer. Cancer Gene Ther. 2017;24(2):48-56. doi:10.1038/cgt.20 16.77

21. Cho S, Yang H, Rhee W. Simultaneous multiplexed detection of exosomal microRNAs and surface proteins for prostate cancer diagnosis. Biosens Bioelectron. 2019;146:111749. doi:10.1016/j. bios.2019.111749

22. Xia X, Wang Y, Huang Y, Zhang H, Lu H, Zheng JC. Exosomal miRNAs in central nervous system diseases: biomarkers, pathological mediators, protective factors and therapeutic agents. Prog Neurobiol. 2019;183:101694. doi:10.1016/j.pneurobio.2019.101 694

23. Betzer O, Perets N, Angel A, et al. In vivo neuroimaging of exosomes using gold nanoparticles. ACS Nano. 2017;11 (11):10883-10893. doi:10.1021/acsnano.7b04495

24. Haney MJ, Klyachko NL, Zhao Y, et al. Exosomes as drug delivery vehicles for Parkinson's disease therapy. J Control Release. 2015;207:18-30. doi:10.1016/j.jconrel.2015.03.033

25. Ha D, Yang N, Nadithe V. Exosomes as therapeutic drug carriers and delivery vehicles across biological membranes: current perspectives and future challenges. Acta Pharm Sin B. 2016;6 (4):287-296. doi:10.1016/j.apsb.2016.02.001

26. Kibria G, Ramos EK, Wan Y, Gius DR, Liu H. Exosomes as a drug delivery system in cancer therapy: potential and challenges. Mol Pharm. 2018;15(9):3625-3633. doi:10.1021/acs. molpharmaceut.8b00277

27. Bourne RRA, Jonas JB, Bron AM, et al. Prevalence and causes of vision loss in high-income countries and in Eastern and Central Europe in 2015: magnitude, temporal trends and projections. $\mathrm{Br}$ J Ophthalmol. 2018;102(5):575-585. doi:10.1136/bjophthalmol2017-311258

28. Sabanayagam C, Cheng C-Y. Global causes of vision loss in 2015: are we on track to achieve the Vision 2020 target? The Lancet Global Health. 2017;5(12):e1164-e1165. doi:10.1016/ s2214-109x(17)30412-6

29. Flaxman SR, Bourne RRA, Resnikoff S, et al. Global causes of blindness and distance vision impairment 1990-2020: a systematic review and meta-analysis. The Lancet Global Health. 2017;5(12):e1221-e1234. doi:10.1016/S2214-109X(17) 30393-5

30. Fricke TR, Tahhan N, Resnikoff S, et al. Global prevalence of presbyopia and vision impairment from uncorrected presbyopia: systematic review, meta-analysis, and modelling. Ophthalmology. 2018;125(10):1492-1499. doi:10.1016/j.ophtha.2018.04.013

31. DelMonte D, Kim T. Anatomy and physiology of the cornea. J Cataract Refract Surg. 2011;37(3):588-598. doi:10.1016/j.jcrs. 2010.12.037

32. Vallabh NA, Romano V, Willoughby CE. Mitochondrial dysfunction and oxidative stress in corneal disease. Mitochondrion. 2017;36:103-113. doi:10.1016/j.mito.2017.05.009

33. Forrester JV, Kuffova L, Dick AD. Autoimmunity, autoinflammation, and infection in uveitis. Am J Ophthalmol. 2018;189:77-85. doi:10.1016/j.ajo.2018.02.019

34. Mathew B, Ravindran S, Liu X, et al. Mesenchymal stem cell-derived extracellular vesicles and retinal ischemia-reperfusion. Biomaterials. 2019;197:146-160. doi:10.1016/j.biomaterials.2019. 01.016
35. Yu B, Li XR, Zhang XM. Mesenchymal stem cell-derived extracellular vesicles as a new therapeutic strategy for ocular diseases. World J Stem Cells. 2020;12(3):178-187. doi:10.4252/wjsc.v12.i3.178

36. Mead B, Tomarev S. Extracellular vesicle therapy for retinal diseases. Prog Retin Eye Res. 2020;79:100849. doi:10.1016/j. preteyeres.2020.100849

37. Li SF, Han Y, Wang F, Su Y. Progress in exosomes and their potential use in ocular diseases. Int $J$ Ophthalmol. 2020;13 (9):1493-1498. doi:10.18240/ijo.2020.09.23

38. Villarroya-Beltri C, Baixauli F, Gutierrez-Vazquez C, SanchezMadrid F, Mittelbrunn M. Sorting it out: regulation of exosome loading. Semin Cancer Biol. 2014;28:3-13. doi:10.1016/j. semcancer.2014.04.009

39. Chen L, Chen R, Kemper S, Brigstock DR. Pathways of production and delivery of hepatocyte exosomes. J Cell Commun Signal. 2018;12(1):343-357. doi:10.1007/s12079-017-0421-7

40. Gurunathan S, Kang MH, Jeyaraj M, Qasim M, Kim JH. Review of the isolation, characterization, biological function, and multifarious therapeutic approaches of exosomes. Cells. 2019;8(4):Apr. doi:10.3390/cells8040307

41. Alenquer M, Amorim MJ. Exosome biogenesis, regulation, and function in viral infection. Viruses. 2015;7(9):5066-5083. doi:10.3390/v7092862

42. Colombo M, Moita C, van Niel G, et al. Analysis of ESCRT functions in exosome biogenesis, composition and secretion highlights the heterogeneity of extracellular vesicles. J Cell Sci. 2013;126(Pt 24):5553-5565. doi:10.1242/jcs.128868

43. Juan T, Fürthauer M. Biogenesis and function of ESCRT-dependent extracellular vesicles. Semin Cell Dev Biol. 2018;74:66-77. doi:10.1016/j.semcdb.2017.08.022

44. Baietti MF, Zhang Z, Mortier E, et al. Syndecan-syntenin-ALIX regulates the biogenesis of exosomes. Nat Cell Biol. 2012;14 (7):677-685. doi:10.1038/ncb2502

45. Hikita T, Kuwahara A, Watanabe R, Miyata M, Oneyama C. Src in endosomal membranes promotes exosome secretion and tumor progression. Sci Rep. 2019;9(1):3265. doi:10.1038/s41598-01939882-z

46. Hyenne V, Labouesse M, Goetz JG. The Small GTPase Ral orchestrates MVB biogenesis and exosome secretion. Small GTPases. 2018;9(6):445-451. doi:10.1080/21541248.2016.1251378

47. Murrow L, Debnath J. Atg12-Atg3 coordinates basal autophagy, endolysosomal trafficking, and exosome release. Mol Cell Oncol. 2018;5(5):e1039191. doi:10.1080/23723556.2015.1039191

48. Yoon S, Kovalenko A, Bogdanov K, Wallach D. MLKL, the protein that mediates necroptosis, also regulates endosomal trafficking and extracellular vesicle generation. Immunity. 2017;47 (1):51-65 e7. doi:10.1016/j.immuni.2017.06.001

49. Zhang J, Li S, Li L, et al. Exosome and exosomal microRNA: trafficking, sorting, and function. Genomics Proteomics Bioinformatics. 2015;13(1):17-24. doi:10.1016/j.gpb.2015.02.001

50. Skotland T, Sandvig K, Llorente A. Lipids in exosomes: current knowledge and the way forward. Prog Lipid Res. 2017;66:30-41. doi:10.1016/j.plipres.2017.03.001

51. Pegtel DM, Gould SJ. Exosomes. Annu Rev Biochem. 2019;88:487-514. doi:10.1146/annurev-biochem-013118-111902

52. Yim N, Ryu S-W, Choi K, et al. Exosome engineering for efficient intracellular delivery of soluble proteins using optically reversible protein-protein interaction module. Nat Commun. 2016;7. doi:10.1038/ncomms12277

53. He C, Zheng S, Luo Y, Wang B. Exosome theranostics: biology and translational medicine. Theranostics. 2018;8(1):237-255. doi:10.7150/thno. 21945

54. Valadi H, Ekstrom K, Bossios A, Sjostrand M, Lee JJ, Lotvall JO. Exosome-mediated transfer of mRNAs and microRNAs is a novel mechanism of genetic exchange between cells. Nat Cell Biol. 2007;9(6):654-659. doi:10.1038/ncb1596 
55. Cheng J, Meng J, Zhu L, Peng Y. Exosomal noncoding RNAs in Glioma: biological functions and potential clinical applications. Mol Cancer. 2020;19(1):66. doi:10.1186/s12943-020-01189-3

56. Farooqi AA, Desai NN, Qureshi MZ, et al. Exosome biogenesis, bioactivities and functions as new delivery systems of natural compounds. Biotechnol Adv. 2018;36(1):328-334. doi:10.1016/j. biotechadv.2017.12.010

57. Abels ER, Breakefield XO. Introduction to extracellular vesicles: biogenesis, RNA cargo selection, content, release, and uptake. Cell Mol Neurobiol. 2016;36(3):301-312. doi:10.1007/s10571016-0366-Z

58. Horibe S, Tanahashi T, Kawauchi S, Murakami Y, Rikitake Y. Mechanism of recipient cell-dependent differences in exosome uptake. BMC Cancer. 2018;18(1):47. doi:10.1186/s12885-0173958-1

59. Ren R, Tan X-H, Zhao J-H, et al. Bone marrow mesenchymal stem cell-derived exosome uptake and retrograde transport can occur at peripheral nerve endings. Artif Cells, Nanomed Biotechnol. 2019;47 (1):2918-2929. doi:10.1080/21691401.2019.1640713

60. McKay TB, Hutcheon AEK, Zieske JD, Ciolino JB. Extracellular vesicles secreted by corneal epithelial cells promote myofibroblast differentiation. Cells. 2020;9(5):1080. doi:10.3390/cells90 51080

61. Samaeekia R, Rabiee B, Putra I, et al. Effect of human corneal mesenchymal stromal cell-derived exosomes on corneal epithelial wound healing. Invest Ophthalmol Vis Sci. 2018;59(12):51 94-5200. doi:10.1167/iovs.18-24803

62. Mead B, Tomarev S. Bone marrow-derived mesenchymal stem cells-derived exosomes promote survival of retinal ganglion cells through miRNA-dependent mechanisms. Stem Cells Transl Med. 2017;6(4):1273-1285. doi:10.1002/sctm.16-0428

63. Thery C, Witwer KW, Aikawa E, et al. Minimal information for studies of extracellular vesicles 2018 (MISEV2018): a position statement of the International Society for Extracellular Vesicles and update of the MISEV2014 guidelines. J Extracell Vesicles. 2018;7(1):1535750. doi:10.1080/20013078.2018.1535750

64. Tkach M, Kowal J, Thery C. Why the need and how to approach the functional diversity of extracellular vesicles. Philos Trans R Soc Lond B Biol Sci. 2018;373(1737):20160479. doi:10.1098/ rstb.2016.0479

65. Witwer KW, Thery C. Extracellular vesicles or exosomes? On primacy, precision, and popularity influencing a choice of nomenclature. J Extracell Vesicles. 2019;8(1):1648167. doi:10. 1080/20013078.2019.1648167

66. Li P, Kaslan M, Lee SH, Yao J, Gao Z. Progress in exosome isolation techniques. Theranostics. 2017;7(3):789-804. doi:10.71 50/thno. 18133

67. Lucchetti D, Fattorossi A, Sgambato A. Extracellular vesicles in oncology: progress and pitfalls in the methods of isolation and analysis. Biotechnol J. 2019;14(1):e1700716. doi:10.1002/biot.20 1700716

68. Théry C, Amigorena S, Raposo G, Clayton A. Isolation and characterization of exosomes from cell culture supernatants and biological fluids. Current Protocols Cell Biol. 2006;Unit 3.22. doi:10.1002/0471143030.cb0322s30

69. Purushothaman A. Exosomes from cell culture-conditioned medium: isolation by ultracentrifugation and characterization Methods Mol Biol. 2019;1952:233-244. doi:10.1007/978-1-49 39-9133-4 19

70. Livshits MA, Khomyakova E, Evtushenko EG, et al. Isolation of exosomes by differential centrifugation: theoretical analysis of a commonly used protocol. Sci Rep. 2015;5:17319. doi:10.1038/ srep 17319

71. Momen-Heravi F. Isolation of extracellular vesicles by ultracentrifugation. Methods Mol Biol. 2017;1660:25-32. doi:10. 1007/978-1-4939-7253-1_3
72. Mincheva-Nilsson L, Baranov V, Nagaeva O, Dehlin E. Isolation and characterization of exosomes from cultures of tissue explants and cell lines. Curr Protoc Immunol. 2016;115(1):1442 1-14 42 21. doi:10.1002/cpim.17

73. Gupta S, Rawat S, Arora V, et al. An improvised one-step sucrose cushion ultracentrifugation method for exosome isolation from culture supernatants of mesenchymal stem cells. Stem Cell Res Ther. 2018;9(1):180. doi:10.1186/s13287-018-0923-0

74. Greening DW, Xu R, Ji H, Tauro BJ, Simpson RJ. A protocol for exosome isolation and characterization: evaluation of ultracentrifugation, density-gradient separation, and immunoaffinity capture methods. Methods Mol Biol. 2015;1295:179-209. doi:10.1007/ 978-1-4939-2550-6_15

75. Li K, Wong DK, Hong KY, Raffai RL. Cushioned-Density Gradient Ultracentrifugation (C-DGUC): a refined and high performance method for the isolation, characterization, and use of exosomes. Methods Mol Biol. 2018;1740:69-83. doi:10.1007/ 978-1-4939-7652-2 7

76. Baranyai T, Herczeg K, Onodi Z, et al. Isolation of exosomes from blood plasma: qualitative and quantitative comparison of ultracentrifugation and size exclusion chromatography methods. PLoS One. 2015;10(12):e0145686. doi:10.1371/journal.pone.014 5686

77. An M, Wu J, Zhu J, Lubman DM. Comparison of an optimized ultracentrifugation method versus size-exclusion chromatography for isolation of exosomes from human serum. J Proteome Res. 2018;17(10):3599-3605. doi:10.1021/acs.jproteome.8b00479

78. Lobb R, Moller A. Size exclusion chromatography: a simple and reliable method for exosome purification. Methods Mol Biol. 2017;1660:105-110. doi:10.1007/978-1-4939-7253-1 9

79. Monguio-Tortajada M, Galvez-Monton C, Bayes-Genis A, Roura S, Borras FE. Extracellular vesicle isolation methods: rising impact of size-exclusion chromatography. Cell Mol Life Sci. 2019;76(12):2369-2382. doi:10.1007/s00018-019-03071-y

80. Oksvold MP, Neurauter A, Pedersen KW. Magnetic bead-based isolation of exosomes. Methods Mol Biol. 2015;1218:465-481. doi:10.1007/978-1-4939-1538-5 27

81. Soares Martins T, Catita J, Martins Rosa I, Henriques AG. Exosome isolation from distinct biofluids using precipitation and column-based approaches. PLoS One. 2018;13(6):e0198820. doi:10.1371/journal.pone.0198820

82. Weng Y, Sui Z, Shan Y, et al. Effective isolation of exosomes with polyethylene glycol from cell culture supernatant for in-depth proteome profiling. Analyst. 2016;141(15):4640-4646. doi:10.10 39/c6an00892e

83. Kalluri R. The biology and function of exosomes in cancer. J Clin Invest. 2016;126(4):1208-1215. doi:10.1172/JCI81135

84. Kourembanas S. Exosomes: vehicles of intercellular signaling, biomarkers, and vectors of cell therapy. Annu Rev Physiol. 2015;77:13-27. doi:10.1146/annurev-physiol-021014-071641

85. Mathivanan S, Ji H, Simpson RJ. Exosomes: extracellular organelles important in intercellular communication. J Proteomics. 2010;73(10):1907-1920. doi:10.1016/j.jprot.2010.06.006

86. French $\mathrm{KC}$, Antonyak MA, Cerione RA. Extracellular vesicle docking at the cellular port: extracellular vesicle binding and uptake. Semin Cell Dev Biol. 2017;67:48-55. doi:10.1016/j. semcdb.2017.01.002

87. Lerner N, Chen I, Schreiber-Avissar S, Beit-Yannai E. Extracellular vesicles mediate anti-oxidative response-in vitro study in the ocular drainage system. Int J Mol Sci. 2020;21 (17):6105. doi:10.3390/ijms21176105

88. Li W, Jin L, Cui Y, Nie A, Xie N, Liang G. Bone marrow mesenchymal stem cells-induced exosomal microRNA-486-3p protects against diabetic retinopathy through TLR4/NF- $\kappa \mathrm{B}$ axis repression. J Endocrinol Invest. 2020. doi:10.1007/s40618-02001405-3 
89. Kurywchak P, Tavormina J, Kalluri R. The emerging roles of exosomes in the modulation of immune responses in cancer. Genome Med. 2018;10(1):23. doi:10.1186/s13073-018-0535-4

90. Greening DW, Gopal SK, Xu R, Simpson RJ, Chen W. Exosomes and their roles in immune regulation and cancer. Semin Cell Dev Biol. 2015;40:72-81. doi:10.1016/j.semcdb.2015.02.009

91. Kim SH, Lechman ER, Bianco N, et al. Exosomes derived from IL-10-treated dendritic cells can suppress inflammation and collagen-induced arthritis. J Immunol. 2005;174(10):6440-6448. doi:10.4049/jimmunol.174.10.6440

92. Kojima M, Costantini TW, Eliceiri BP, Chan TW, Baird A, Coimbra R. Gut epithelial cell-derived exosomes trigger posttrauma immune dysfunction. J Trauma Acute Care Surg. 2018;84(2):257-264. doi:10.1097/TA.0000000000001748

93. Whiteside TL. Exosomes and tumor-mediated immune suppression. J Clin Invest. 2016;126(4):1216-1223. doi:10.1172/ JCI81136

94. Whiteside TL. Tumor-derived exosomes and their role in cancer progression. Adv Clin Chem. 2016;74:103-141. doi:10.1016/bs. acc.2015.12.005

95. Knickelbein JE, Liu B, Arakelyan A, et al. Modulation of immune responses by extracellular vesicles from retinal pigment epithelium. Invest Ophthalmol Vis Sci. 2016;57(10):4101-4107. doi:10.1167/iovs.15-18353

96. Chen B, Li Q, Zhao B, Wang Y. Stem cell-derived extracellular vesicles as a novel potential therapeutic tool for tissue repair. Stem Cells Transl Med. 2017;6(9):1753-1758. doi:10.1002/ sctm. 16-0477

97. Bjorge IM, Kim SY, Mano JF, Kalionis B, Chrzanowski W. Extracellular vesicles, exosomes and shedding vesicles in regenerative medicine - a new paradigm for tissue repair. Biomater Sci. 2017;6(1):60-78. doi:10.1039/c7bm00479f

98. Yue Y, Garikipati VNS, Verma SK, Goukassian DA, Kishore R. Interleukin-10 deficiency impairs reparative properties of bone marrow-derived endothelial progenitor cell exosomes. Tissue Eng Part A. 2017;23(21-22):1241-1250. doi:10.1089/ten.TEA.2017.0084

99. Zhang S, Chuah SJ, Lai RC, Hui JHP, Lim SK, Toh WS. MSC exosomes mediate cartilage repair by enhancing proliferation, attenuating apoptosis and modulating immune reactivity. Biomaterials. 2018;156:16-27. doi:10.1016/j.biomaterials.2017.11.028

100. Hyung S, Jeong J, Shin K, et al. Exosomes derived from chemically induced human hepatic progenitors inhibit oxidative stress induced cell death. Biotechnol Bioeng. 2020;117(9):2658-2667. doi:10.1002/bit.27447

101. Hu C, Li L. Improvement of mesenchymal stromal cells and their derivatives for treating acute liver failure. $J \mathrm{Mol} \mathrm{Med} \mathrm{(Berl).}$ 2019;97(8):1065-1084. doi:10.1007/s00109-019-01804-x

102. Nojima H, Freeman CM, Schuster RM, et al. Hepatocyte exosomes mediate liver repair and regeneration via sphingosine-1-phosphate. J Hepatol. 2016;64(1):60-68. doi:10.1016/j.jhep.2015.07.030

103. Atienzar-Aroca S, Flores-Bellver M, Serrano-Heras G, et al. Oxidative stress in retinal pigment epithelium cells increases exosome secretion and promotes angiogenesis in endothelial cells. J Cell Mol Med. 2016;20(8):1457-1466. doi:10.1111/jcmm.12834

104. Barile L, Vassalli G. Exosomes: therapy delivery tools and biomarkers of diseases. Pharmacol Ther. 2017;174:63-78. doi:10.10 16/j.pharmthera.2017.02.020

105. Li Y, Zheng Q, Bao C, et al. Circular RNA is enriched and stable in exosomes: a promising biomarker for cancer diagnosis. Cell Res. 2015;25(8):981-984. doi:10.1038/cr.2015.82

106. Xiao Y, Li Y, Yuan Y, et al. The potential of exosomes derived from colorectal cancer as a biomarker. Clin Chim Acta. 2019;490:186-193. doi:10.1016/j.cca.2018.09.007

107. Melo SA, Luecke LB, Kahlert C, et al. Glypican-1 identifies cancer exosomes and detects early pancreatic cancer. Nature. 2015;523(7559):177-182. doi:10.1038/nature14581
108. Brinton LT, Sloane HS, Kester M, Kelly KA. Formation and role of exosomes in cancer. Cell Mol Life Sci. 2015;72(4):659-671. doi:10.1007/s00018-014-1764-3

109. Hesari A, Golrokh Moghadam SA, Siasi A, et al. Tumor-derived exosomes: potential biomarker or therapeutic target in breast cancer? J Cell Biochem. 2018;119(6):4236-4240. doi:10.1002/ jcb. 26364

110. Skotland T, Ekroos K, Kauhanen D, et al. Molecular lipid species in urinary exosomes as potential prostate cancer biomarkers. Eur $J$ Cancer. 2017;70:122-132. doi:10.1016/j.ejca.2016.10.011

111. Dismuke WM, Challa P, Navarro I, Stamer WD, Liu Y. Human aqueous humor exosomes. Exp Eye Res. 2015;132:73-77. doi:10.1016/j.exer.2015.01.019

112. Liu Y, Bailey JC, Helwa I, et al. A common variant in MIR182 is associated with primary open-angle glaucoma in the NEIGHBORHOOD consortium. Invest Opthalmol Visual Sci. 2016;57(10):4528. doi:10.1167/iovs.16-19688

113. Zhao Y, Weber SR, Lease J, et al. Liquid biopsy of vitreous reveals an abundant vesicle population consistent with the size and morphology of exosomes. Transl Vis Sci Technol. 2018;7 (3):6. doi:10.1167/tvst.7.3.6

114. Klingeborn M, Dismuke WM, Skiba NP, Kelly U, Stamer WD, Bowes Rickman C. Directional exosome proteomes reflect polarity-specific functions in retinal pigmented epithelium monolayers. Sci Rep. 2017;7(1):4901. doi:10.1038/s41598-01705102-9

115. Kang GY, Bang JY, Choi AJ, et al. Exosomal proteins in the aqueous humor as novel biomarkers in patients with neovascular age-related macular degeneration. J Proteome Res. 2014;13 (2):581-595. doi:10.1021/pr400751k

116. Klingeborn M, Skiba NP, Stamer WD, Bowes Rickman C. Isolation of retinal exosome biomarkers from blood by targeted immunocapture. Adv Exp Med Biol. 2019;1185:21-25. doi:10.1007/978-3-030-27378-1 4

117. Luan X, Sansanaphongpricha $\bar{K}$, Myers I, Chen H, Yuan H, Sun D. Engineering exosomes as refined biological nanoplatforms for drug delivery. Acta Pharmacol Sin. 2017;38(6):754-763. doi:10.1038/aps.2017.12

118. Ran N, Gao X, Dong X, et al. Effects of exosome-mediated delivery of myostatin propeptide on functional recovery of $\mathrm{mdx}$ mice. Biomaterials. 2020;236:119826. doi:10.1016/j.biomaterials.2020.11 9826

119. Gao X, Ran N, Dong X, et al. Anchor peptide captures, targets, and loads exosomes of diverse origins for diagnostics and therapy. Sci Transl Med. 2018;10(444):eaat0195. doi:10.1126/scitranslmed. aat0195

120. Sterzenbach U, Putz U, Low LH, Silke J, Tan SS, Howitt J. Engineered exosomes as vehicles for biologically active proteins. Mol Ther. 2017;25(6):1269-1278. doi:10.1016/j.ymthe. 2017.03.030

121. Chen R, Huang H, Liu H, et al. Friend or Foe? Evidence indicates endogenous exosomes can deliver functional gRNA and Cas9 protein. Small. 2019;15(38):e1902686. doi:10.1002/smll.201902 686

122. Wang QL, Zhuang X, Sriwastva MK, et al. Blood exosomes regulate the tissue distribution of grapefruit-derived nanovector via CD36 and IGFR1 pathways. Theranostics. 2018;8(18):49 12-4924. doi:10.7150/thno.27608

123. Wassmer SJ, Carvalho LS, Gyorgy B, Vandenberghe LH, Maguire CA. Exosome-associated AAV2 vector mediates robust gene delivery into the murine retina upon intravitreal injection. Sci Rep. 2017;7:45329. doi:10.1038/srep45329

124. Zhang W, Wang Y, Kong Y. Exosomes derived from mesenchymal stem cells modulate miR-126 to ameliorate hyperglycemia-induced retinal inflammation via targeting HMGB1. Invest Ophthalmol Vis Sci. 2019;60(1):294-303. doi:10.1167/iovs.18-25617 
125. Fu W, Lei C, Liu S, et al. CAR exosomes derived from effector CAR-T cells have potent antitumour effects and low toxicity. Nat Commun. 2019;10(1):4355. doi:10.1038/s41467-019-12321-3

126. Chen L, Feng Z, Yue $\mathrm{H}$, et al. Exosomes derived from HIV-1-infected cells promote growth and progression of cancer via HIV TAR RNA. Nat Commun. 2018;9(1):4585. doi:10.1038/ s41467-018-07006-2

127. Barclay RA, Schwab A, DeMarino C, et al. Exosomes from uninfected cells activate transcription of latent HIV-1. J Biol Chem. 2017;292(28):11682-11701. doi:10.1074/jbc.M117.793521

128. Cho YE, Seo W, Kim DK, et al. Exogenous exosomes from mice with acetaminophen-induced liver injury promote toxicity in the recipient hepatocytes and mice. Sci Rep. 2018;8(1):16070. doi:10.1038/s41598-018-34309-7

129. Gao M, Dong Z, Sun J, et al. Liver-derived exosome-laden lncRNA MT1DP aggravates cadmium-induced nephrotoxicity. Environ Pollut. 2020;258:113717. doi:10.1016/j.envpol.2019.11 3717

130. Sardar Sinha M, Ansell-Schultz A, Civitelli L, et al. Alzheimer's disease pathology propagation by exosomes containing toxic amyloid-beta oligomers. Acta Neuropathol. 2018;136(1):41-56. doi:10.1007/s00401-018-1868-1

131. Huang C, Fisher KP, Hammer SS, Navitskaya S, Blanchard GJ, Busik JV. Plasma exosomes contribute to microvascular damage in diabetic retinopathy by activating the classical complement pathway. Diabetes. 2018;67(8):1639-1649. doi:10.2337/db171587

132. Ke Y, Fan X, Rui H, et al. Exosomes derived from RPE cells under oxidative stress mediate inflammation and apoptosis of normal RPE cells through Apaf1/caspase-9 axis. $J$ Cell Biochem. 2020;121(12):4849-4861. doi:10.1002/jcb.29713

133. Sies H. Oxidative stress: a concept in redox biology and medicine. Redox Biol. 2015;4:180-183. doi:10.1016/j.redox.20 15.01 .002

134. Chettimada S, Lorenz DR, Misra V, et al. Exosome markers associated with immune activation and oxidative stress in HIV patients on antiretroviral therapy. Sci Rep. 2018;8(1):7227. doi:10.1038/s41598-018-25515-4

135. Xiao J, Pan Y, Li XH, et al. Cardiac progenitor cell-derived exosomes prevent cardiomyocytes apoptosis through exosomal miR-21 by targeting PDCD4. Cell Death Dis. 2016;7(6):e2277. doi:10.1038/cddis.2016.181

136. Saeed-Zidane M, Linden L, Salilew-Wondim D, et al. Cellular and exosome mediated molecular defense mechanism in bovine granulosa cells exposed to oxidative stress. PLoS One. 2017;12 (11):e0187569. doi:10.1371/journal.pone.0187569

137. Hanus J, Anderson C, Wang S. RPE necroptosis in response to oxidative stress and in AMD. Ageing Res Rev. 2015;24(Pt B):286-298. doi:10.1016/j.arr.2015.09.002

138. Ung L, Pattamatta U, Carnt N, Wilkinson-Berka JL, Liew G, White AJR. Oxidative stress and reactive oxygen species: a review of their role in ocular disease. Clin Sci (Lond). 2017;131(24):2865-2883. doi:10.1042/CS20171246

139. Datta S, Cano M, Ebrahimi K, Wang L, Handa JT. The impact of oxidative stress and inflammation on RPE degeneration in non-neovascular AMD. Prog Retin Eye Res. 2017;60:201-218. doi:10.1016/j.preteyeres.2017.03.002

140. Stitt AW, Curtis TM, Chen M, et al. The progress in understanding and treatment of diabetic retinopathy. Prog Retin Eye Res. 2016;51:156-186. doi:10.1016/j.preteyeres.2015.08.001

141. Wong TY, Cheung CM, Larsen M, Sharma S, Simo R. Diabetic retinopathy. Nat Rev Dis Primers. 2016;2:16012. doi:10.1038/ nrdp.2016.12

142. Walker R. Diabetic retinopathy: protecting the vision of people with diabetes. Br J Community Nurs. 2004;9(12):545-547. doi:10.12968/bjen.2004.9.12.17245
143. Mu H, Wang Y, Wei H, et al. Collagen peptide modified carboxymethyl cellulose as both antioxidant drug and carrier for drug delivery against retinal ischaemia/reperfusion injury. $J$ Cell Mol Med. 2018;22(10):5008-5019. doi:10.1111/jcmm.13768

144. Liu L, Sun Q, Wang R, et al. Methane attenuates retinal ischemia/ reperfusion injury via anti-oxidative and anti-apoptotic pathways. Brain Res. 2016;1646:327-333. doi:10.1016/j.brainres.2016.05.037

145. Moisseiev E, Anderson JD, Oltjen S, et al. Protective effect of intravitreal administration of exosomes derived from mesenchymal stem cells on retinal ischemia. Curr Eye Res. 2017;42 (10):1358-1367. doi:10.1080/02713683.2017.1319491

146. Tokarz A, Szuścik I, Kuśnierz-Cabala B, et al. Extracellular vesicles participate in the transport of cytokines and angiogenic factors in diabetic patients with ocular complications. Folia Med Cracov. 2015;55(4):35-48.

147. Maisto R, Trotta MC, Petrillo F, et al. Resolvin D1 modulates the intracellular VEGF-related miRNAs of retinal photoreceptors challenged with high glucose. Front Pharmacol. 2020;11:235. doi:10.3389/fphar.2020.00235

148. Liu C, Ge HM, Liu BH, et al. Targeting pericyte-endothelial cell crosstalk by circular RNA-cPWWP2A inhibition aggravates diabetes-induced microvascular dysfunction. Proc Natl Acad Sci U S A. 2019;116(15):7455-7464. doi:10.1073/pnas.1814874116

149. Zhang W, Dong X, Wang T, Kong Y. Exosomes derived from platelet-rich plasma mediate hyperglycemia-induced retinal endothelial injury via targeting the TLR4 signaling pathway. Exp Eye Res. 2019;189:107813. doi:10.1016/j.exer.2019.107813

150. Kamalden TA, Macgregor-Das AM, Kannan SM, et al. Exosomal MicroRNA-15a transfer from the pancreas augments diabetic complications by inducing oxidative stress. Antioxid Redox Signal. 2017;27(13):913-930. doi:10.1089/ars.2016.6844

151. Katome T, Namekata K, Mitamura Y, et al. Expression of intraocular peroxisome proliferator-activated receptor gamma in patients with proliferative diabetic retinopathy. $J$ Diabetes Complications. 2015;29(2):275-281. doi:10.1016/j.jdiacomp.2014.10.010

152. Hsu MY, Chiu CC, Wang JY, et al. Paper-based microfluidic platforms for understanding the role of exosomes in the pathogenesis of major blindness-threatening diseases. Nanomaterials (Basel). 2018;5. doi:10.3390/nano8050310

153. Tong Y, Zhou YL, Wang YX, Zhao PQ, Wang ZY. Retinal pigment epithelium cell-derived exosomes: possible relevance to $\mathrm{CNV}$ in wet-age related macular degeneration. Med Hypotheses. 2016;97:98-101. doi:10.1016/j.mehy.2016.10.027

154. Shah N, Ishii M, Brandon C, et al. Extracellular vesicle-mediated long-range communication in stressed retinal pigment epithelial cell monolayers. Biochimica Et Biophysica Acta Mol Basis Dis. 2018;1864(8):2610-2622. doi:10.1016/j.bbadis.2018.04.016

155. Hajrasouliha AR, Jiang G, Lu Q, et al. Exosomes from retinal astrocytes contain antiangiogenic components that inhibit laser-induced choroidal neovascularization. $J$ Biol Chem. 2013;288(39):28058-28067. doi:10.1074/jbc.M113.470765

156. Atienzar-Aroca S, Serrano-Heras G, Freire Valls A, et al. Role of retinal pigment epithelium-derived exosomes and autophagy in new blood vessel formation. $J$ Cell Mol Med. 2018;22 (11):5244-5256. doi:10.1111/jcmm.13730

157. Wang AL, Lukas TJ, Yuan M, Du N, Tso MO, Neufeld AH. Autophagy, exosomes and drusen formation in age-related macular degeneration. Autophagy. 2009;5(4):563-564. doi:10.4161/ auto.5.4.8163

158. Aboul Naga SH, Dithmer M, Chitadze G, et al. Intracellular pathways following uptake of bevacizumab in RPE cells. Exp Eye Res. 2015;131:29-41. doi:10.1016/j.exer.2014.12.010

159. Elbay A, Ercan Ç, Akbaş F, Bulut H, Ozdemir H. Three new circulating microRNAs may be associated with wet age-related macular degeneration. Scand J Clin Lab Invest. 2019;79(6): 388-394. doi:10.1080/00365513.2019.1637931 
160. Biasutto L, Chiechi A, Couch R, Liotta LA, Espina V. Retinal pigment epithelium (RPE) exosomes contain signaling phosphoproteins affected by oxidative stress. Exp Cell Res. 2013;319 (13):2113-2123. doi:10.1016/j.yexcr.2013.05.005

161. Bai L, Shao H, Wang H, et al. Effects of mesenchymal stem cell-derived exosomes on experimental autoimmune uveitis. Sci Rep. 2017;7(1):4323. doi:10.1038/s41598-017-04559-y

162. Harrell CR, Simovic Markovic B, Fellabaum C, et al. Therapeutic potential of mesenchymal stem cell-derived exosomes in the treatment of eye diseases. Adv Exp Med Biol. 2018;1089:47-57. doi:10.1007/5584_2018_219

163. Davis BM, Crawley L, Pahlitzsch M, Javaid F, Cordeiro MF. Glaucoma: the retina and beyond. Acta Neuropathol. 2016;132 (6):807-826. doi:10.1007/s00401-016-1609-2

164. Razeghinejad MR, Myers JS, Katz LJ. Iatrogenic glaucoma secondary to medications. Am J Med. 2011;124(1):20-25. doi:10.1016/j.amjmed.2010.08.011

165. Weinreb RN, Aung T, Medeiros FA. The pathophysiology and treatment of glaucoma: a review. JAMA. 2014;311 (18):1901-1911. doi:10.1001/jama.2014.3192

166. Casson RJ, Chidlow G, Wood JP, Crowston JG, Goldberg I. Definition of glaucoma: clinical and experimental concepts. Clin Exp Ophthalmol. 2012;40(4):341-349. doi:10.1111/j.1442-9071.2012. 02773.x

167. Almasieh M, Wilson A, Morquette B, Cueva Vargas J, Di Polo A. The molecular basis of retinal ganglion cell death in glaucoma. Prog Retin Eye Res. 2012;31(2):152-181. doi:10.1016/j. preteyeres.2011.11.002

168. Harrell CR, Fellabaum C, Arsenijevic A, Markovic BS, Djonov V, Volarevic V. Therapeutic potential of mesenchymal stem cells and their secretome in the treatment of glaucoma. Stem Cells Int. 2019;2019:1-11. doi:10.1155/2019/7869130

169. Lerner N, Schreiber-Avissar S, Beit-Yannai E. Extracellular vesicle-mediated crosstalk between NPCE cells and TM cells result in modulation of Wnt signalling pathway and ECM remodelling. J Cell Mol Med. 2020;24(8):4646-4658. doi:10.1111/jcmm.15129

170. Lerner N, Avissar S, Beit-Yannai E. Extracellular vesicles mediate signaling between the aqueous humor producing and draining cells in the ocular system. PLoS One. 2017;12(2):e0171153. doi:10.1371/journal.pone.0171153

171. Liu Y, Allingham RR, Qin X, et al. Gene expression profile in human trabecular meshwork from patients with primary open-angle glaucoma. Invest Opthalmol Visual Sci. 2013;54 (9):6382. doi:10.1167/iovs.13-12128

172. Stamer WD, Hoffman EA, Luther JM, Hachey DL, Schey KL. Protein profile of exosomes from trabecular meshwork cells. J Proteomics. 2011;74(6):796-804. doi:10.1016/j.jprot.2011.02.024

173. Mead B, Ahmed Z, Tomarev S. Mesenchymal stem cell-derived small extracellular vesicles promote neuroprotection in a genetic DBA/2J mouse model of glaucoma. Invest Ophthalmol Vis Sci. 2018;59(13):5473-5480. doi:10.1167/iovs.18-25310

174. Pan D, Chang X, Xu M, et al. UMSC-derived exosomes promote retinal ganglion cells survival in a rat model of optic nerve crush. $J$ Chem Neuroanat. 2019;96:134-139. doi:10.1016/j.jchemneu. 2019.01.006
175. Coulson-Thomas VJ, Caterson B, Kao WWY. Transplantation of human umbilical mesenchymal stem cells cures the corneal defects of mucopolysaccharidosis VII mice. Stem Cells. 2013;31 (10):2116-2126. doi:10.1002/stem.1481

176. Han KY, Dugas-Ford J, Seiki M, Chang JH, Azar DT. Evidence for the Involvement of MMP14 in MMP2 processing and recruitment in exosomes of corneal fibroblasts. Invest Ophthalmol Vis Sci. 2015;56(9):5323-5329. doi:10.1167/iovs.14-14417

177. Kong L, Fry M, Al-Samarraie M, Gilbert C, Steinkuller PG. An update on progress and the changing epidemiology of causes of childhood blindness worldwide. J AAPOS. 2012;16(6):501-507. doi:10.1016/j.jaapos.2012.09.004

178. Fulton AB, Hansen RM, Moskowitz A, Akula JD. The neurovascular retina in retinopathy of prematurity. Prog Retin Eye Res. 2009;28(6):452-482. doi:10.1016/j.preteyeres.2009.06.003

179. Hansen RM, Moskowitz A, Akula JD, Fulton AB. The neural retina in retinopathy of prematurity. Prog Retin Eye Res. 2017;56:32-57. doi:10.1016/j.preteyeres.2016.09.004

180. Hellström A, Smith LEH, Dammann O. Retinopathy of prematurity. The Lancet. 2013;382(9902):1445-1457. doi:10.10 16/s0140-6736(13)60178-6

181. $\mathrm{Xu} \mathrm{W}, \mathrm{Wu} \mathrm{Y,} \mathrm{Hu} \mathrm{Z}$, et al. Exosomes from microglia attenuate photoreceptor injury and neovascularization in an animal model of retinopathy of prematurity. Mol Ther Nucleic Acids. 2019;16:778-790. doi:10.1016/j.omtn.2019.04.029

182. Salter MW, Beggs S. Sublime microglia: expanding roles for the guardians of the CNS. Cell. 2014;158(1):15-24. doi:10.1016/j. cell.2014.06.008

183. Ebneter A, Kokona D, Schneider N, Zinkernagel MS. Microglia activation and recruitment of circulating macrophages during ischemic experimental branch retinal vein occlusion. Invest Ophthalmol Vis Sci. 2017;58(2):944-953. doi:10.1167/iovs.16-20474

184. Lande K, Gupta J, Ranjan R, et al. Exosomes: insights from retinoblastoma and other eye cancers. Int J Mol Sci. 2020;21 (19). doi:10.3390/ijms21197055

185. Chattopadhyay C, Kim DW, Gombos DS, et al. Uveal melanoma: from diagnosis to treatment and the science in between. Cancer. 2016;122(15):2299-2312. doi:10.1002/cncr.29727

186. Carvajal RD, Schwartz GK, Tezel T, Marr B, Francis JH, Nathan PD. Metastatic disease from uveal melanoma: treatment options and future prospects. $\mathrm{Br} J$ Ophthalmol. 2017;101 (1):38-44. doi:10.1136/bjophthalmol-2016-309034

187. Eldh M, Olofsson Bagge R, Lässer C, et al. MicroRNA in exosomes isolated directly from the liver circulation in patients with metastatic uveal melanoma. BMC Cancer. 2014;14:962. doi:10.1186/1471-2407-14-962

188. Ragusa M, Barbagallo C, Statello L, et al. miRNA profiling in vitreous humor, vitreal exosomes and serum from uveal melanoma patients: pathological and diagnostic implications. Cancer Biol Ther. 2015;16 (9):1387-1396. doi:10.1080/15384047.2015.1046021
International Journal of Nanomedicine

\section{Publish your work in this journal}

The International Journal of Nanomedicine is an international, peerreviewed journal focusing on the application of nanotechnology in diagnostics, therapeutics, and drug delivery systems throughout the biomedical field. This journal is indexed on PubMed Central, MedLine, CAS, SciSearch ${ }^{\mathbb{R}}$, Current Contents ${ }^{\mathbb{R}} /$ Clinical Medicine, $^{2}$
Journal Citation Reports/Science Edition, EMBase, Scopus and the Elsevier Bibliographic databases. The manuscript management system is completely online and includes a very quick and fair peer-review system, which is all easy to use. Visit http://www.dovepress.com/ testimonials.php to read real quotes from published authors. 